REPORT

\title{
Diversity in the New York City Department of Cultural Affairs Community
}

January 28, 2016 (updated on April 21, 2016)

Roger C. Schonfeld

Liam Sweeney

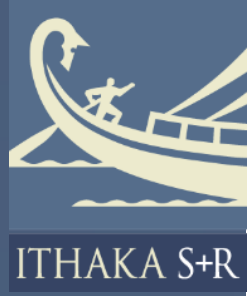




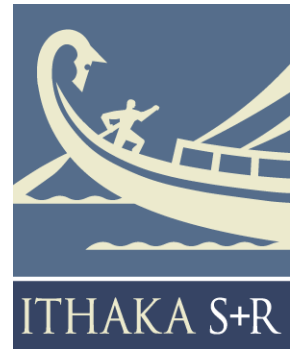

Ithaka $\mathrm{S}+\mathrm{R}$ is a strategic consulting and research service provided by ITHAKA, a not-for-profit organization dedicated to helping the academic community use digital technologies to preserve the scholarly record and to advance research and teaching in sustainable ways. Ithaka $\mathrm{S}+\mathrm{R}$ focuses on the transformation of scholarship and teaching in an online environment, with the goal of identifying the critical issues facing our community and acting as a catalyst for change. JSTOR, a research and learning platform, and Portico, a digital preservation service, are also part of ITHAKA.
Copyright 2016 ITHAKA. This work is licensed under a Creative Commons Attribution-NonCommercial 4.0 International License. To view a copy of the license, please see http://creativecommons.org/licenses/by-nc/4.0/.

ITHAKA is interested in disseminating this brief as widely as possible. Please contact us with any questions about using the report: research@ithaka.org. 


\section{Background}

New York City is one of the most diverse cities in the United States at a city level, ranking fourth in the country based on 2010 census data. ${ }^{1}$ There are over 1,000 cultural organizations in the five boroughs, each with specific ties to communities, each with vastly different organizational structures and sizes, and each integral to the diversity of culture that defines New York City. Over the summer of 2015 many of these organizations participated in a survey to measure one specific aspect of this diversitythat of their employees and board members.

Quantifying diversity in labor markets is an inherently fraught pursuit, in part because our techniques for recording this data, our nomenclature, our definitions must be necessarily blunt in order to reduce the richness of characteristics we use to categorize ourselves and others (race, ethnicity, gender, age, disability, to name only a few) into discrete categories. In spite of this, there is still an opportunity to collect and analyze existing data for a given community in order to generate a baseline to help measure change over time.

This diversity survey developed out of a similar effort to measure the diversity of North American museums, conducted last year. ${ }^{2}$ With the help of the New York City Department of Cultural Affairs (known as DCLA) and generous funding from the Mertz Gilmore and Rockefeller Brothers 3 foundations, we have modified our previous survey to fit the characteristics of the community of cultural organizations that receives support from DCLA.

\footnotetext{
${ }^{1}$ Several figures in this paper were updated on April 21, 2016. Previously, in the binary analysis of Figures 4-11, those categorized as "Decline to State" were grouped, in error, with "Female" in the bottom percentage graphs. The updated graphs exclude "Decline to State." This change decreased the percentage female of Technical/Production staff by $4 \%$. Other graphs were affected by 1 or $2 \%$. Figure 20 has also been modified. Board members who were categorized as "Decline to State" weren't previously included as a category in Figure 20. While including them now does not change the percentage totals in other race/ethnicity categories, it does drop the percentage of white board members by $3 \%$.

As to the diversity of the city, when considering diversity at a neighborhood level New York is much less diverse, dropping in national rankings from $4^{\text {th }}$ to $49^{\text {th }}$ : Nate Silver, "The Most Diverse Cities Are Often The Most Segregated," FiveThirtyEight, May 1, 2015, accessed January 14, 2016, http://fivethirtyeight.com/features/the-most-diverse-cities-areoften-the-most-segregated/.

${ }^{2}$ Roger Schonfeld, Mariët Westermann, and Liam Sweeney, "Art Museum Staff Demographic Survey," The Andrew W. Mellon Foundation, July 29, 2015, https://mellon.org/media/filer public/ba/99/ba99e53a-48d5-4038-80e166f9ba1c020e/awmf museum diversity report aamd 7-28-15.pdf.

${ }^{3}$ This report was made possible in part with support from the Rockefeller Brothers Fund. The opinions and views of the authors do not necessarily state or reflect those of the Fund.
} 
This report presents research findings that analyze the demographics of those organizations, the way they feel about barriers to increasing diversity, and initiatives that have been successful toward that end.

\section{Methodology}

Ithaka $\mathrm{S}+\mathrm{R}$ developed the survey with the advice of Deputy Commissioner Edwin Torres and DCLA staff, as well as an advisory committee comprised of the leadership of several DCLA grantee organizations, found in Table 1.

Table 1: Advisory Committee

\begin{tabular}{ll}
\hline Name & Organization \\
\hline Andrea Louie & Asian American Arts Alliance \\
\hline Lane Harwell & Dance/NYC \\
\hline Sam Miller & Lower Manhattan Cultural Council \\
\hline Gus Schulenberg & Theatre Communications Group, Inc. \\
\hline Caron Atlas & Art+Democracy/Naturally-Occurring Cultural Districts NY \\
\hline Herman Smith & Wildlife Conservation Society \\
\hline
\end{tabular}

The questionnaire was split into two components: a spreadsheet that each DCLA grantee organization was asked to fill out indicating the demographic categories into which each of its employees fell, and a survey questionnaire, which focused on perceptions of diversity, barriers to increasing diversity, and successful initiatives toward fostering diversity on an organizational level.

DCLA provided Ithaka $\mathrm{S}+\mathrm{R}$ with a list of 1,061 organizations to be included in the survey population. This group included fiscal year 2016 Capital Fund recipients, Cultural Development Fund recipients, and members of the Cultural Institutions Group. 
In the spreadsheet, we requested demographic and employment information in a variety of categories. We asked respondents to categorize each employee into one of 22 job types as listed below:

- Conservators

- Curators

- Designer

- Membership/Constituent Services

- IT/Web Development

- Retail/Merchandise

- Editorial

- Community Engagement

- Librarian

- Artist/Performer

- Education
- Technical/Production

- Visitor/Patron Services

- Support/Administration

- Programming

- Facilities

- $\quad$ Security

- Development

- Leadership

- Finance

- $\quad$ Marketing/PR

- Project/Exhibition

We asked respondents to categorize each employee by race and Hispanic/Latino status utilizing the 2000 U.S. Census categories that are used for various reporting purposes as indicated in Table 2.4 We recognize that these categories are inadequate, since many individuals do not identify with these groups. 5 The choice to use census categories was driven by our project objective to provide a strong community-wide analysis and comparative analysis against census and other data sources as well as our decision to gather data from institutions rather than directly from individuals. We supplemented the category requests with an open-ended option to provide more specific identity information for a given individual.

\footnotetext{
${ }^{4}$ These categories were adopted by the federal government for equal opportunity reporting purposes and therefore are in common use at many institutions in our survey population. For more details, see "EEO-1 Instruction Booklet," EEO-1 Instruction Booklet, 2006, accessed January 13, 2016. http://www.eeoc.gov/employers/eeo1survey/2007instructions.cfm.

${ }^{5}$ The Census is considering several changes for the 2020 census to try to rectify some of these issues: Ben Casselman, "The Census Is Still Trying To Find The Best Way To Track Race In America," FiveThirtyEight, November 26, 2014, accessed January 13, 2016, http://fivethirtyeight.com/features/the-census-is-still-trying-to-find-thebest-way-to-track-race-in-america/.
} 
Table 2: Race and Ethnicity Categories

\begin{tabular}{|c|c|}
\hline Race & Description \\
\hline White & $\begin{array}{l}\text { A person having origins in any of the original peoples of } \\
\text { Europe, the Middle East, or North Africa. }\end{array}$ \\
\hline Black or African American & $\begin{array}{l}\text { A person having origins in any of the Black racial groups of } \\
\text { Africa. }\end{array}$ \\
\hline $\begin{array}{l}\text { American Indian or } \\
\text { Alaskan Native }\end{array}$ & $\begin{array}{l}\text { A person having origins in any of the original peoples of North } \\
\text { and South America (including Central America) and who } \\
\text { maintains tribal affiliation or community attachment. }\end{array}$ \\
\hline Asian & $\begin{array}{l}\text { A person having origins in any of the original peoples of the } \\
\text { Far East, Southeast Asia, or the Indian subcontinent } \\
\text { including, for example, Cambodia, China, India, Japan, Korea, } \\
\text { Malaysia, Pakistan, the Philippine Islands, Thailand, and } \\
\text { Vietnam. }\end{array}$ \\
\hline $\begin{array}{l}\text { Native Hawaiian or Other } \\
\text { Pacific Islander }\end{array}$ & $\begin{array}{l}\text { A person having origins in any of the original peoples of } \\
\text { Hawaii, Guam, Samoa, or other Pacific Islands. }\end{array}$ \\
\hline Two or More Races & $\begin{array}{l}\text { All persons who identify with more than one of the above five } \\
\text { races. }\end{array}$ \\
\hline \multicolumn{2}{|l|}{ Decline to state } \\
\hline Ethnicity & Description \\
\hline \multirow[t]{2}{*}{ Hispanic or Latino } & $\begin{array}{l}\text { A person of Cuban, Mexican, Puerto Rican, South or Central } \\
\text { American, or other Spanish culture or origin regardless of } \\
\text { race. }\end{array}$ \\
\hline & Decline to state \\
\hline
\end{tabular}

We asked respondents to categorize each employee by gender (male, female, does not identify as either male or female, or decline to state), employment status (full time, part time, independent contractor, or intern) and level (senior, mid, and junior). We defined level as follows-senior: reports to the board or CEO; mid: supervised by staff but has independent financial, programmatic, or operational responsibilities; junior: has no 
direct reports and work is directly supervised. Finally, we asked for information on disability status, decade of birth, and decade of employment. ${ }^{6}$

After submitting the spreadsheet the respondent moved on to a questionnaire about the organization's perception of the diversity of their workforce, as well as barriers and initiatives around increasing diversity of staff and programming. This included multiple choice, multiple select, free text, and yes/no questions. The questionnaire was designed so that in some cases the respondents' answer determined the next question they would receive.

Under the signature of Commissioner Tom Finkelpearl, the survey invitation message was sent to the executive directors (or equivalent) of recent DCLA funding recipients on July 20th, 2015. The invitation stated that participation was required in order to be eligible for FY2017 funding from DCLA. Several reminder messages were issued by both Commissioner Finkelpearl and directly from Ithaka $\mathrm{S}+\mathrm{R}$. We extended the survey closing date by a two-week period to allow the late responses to be included.

When the survey closed in late September, we had received the following responses:

Table 3: Response Rate

\begin{tabular}{lll}
\hline & $\begin{array}{l}\text { Number of } \\
\text { Responses }\end{array}$ & Response Rate \\
\hline Spreadsheets Returned & 922 & $87 \%$ \\
\hline Response Rate & 987 & $93 \%$ \\
\hline
\end{tabular}

The 922 spreadsheets were appended into a single dataset and normalized. This resulted in a dataset with 48,280 rows, each representing a single employee, volunteer, or board member. In cases of misspellings or obvious mis-categorizations (such as Caucasian instead of white) the data were corrected. Beyond those obvious corrections the data were preserved in as close to their original form as possible.

In the presentation of results, we separated board members and volunteers from all other employees. The findings cover all other employees unless otherwise specified.

\footnotetext{
${ }^{6}$ We considered asking about LGBTQ status but determined that there would be regulatory or legal issues associated with employers tracking or reporting these data to us.
} 


\section{Findings}

The final data set included 48,280 total records representing staff, board, and volunteers at various institution types and sizes. 36,441 of records represent paid staff. Fifty percent of the organizations have fewer than 10 employees representing $6 \%$ of the total staff. On the other side of the spectrum, four organizations with over 1,000 employees compose $14 \%$ of the total employees in the dataset. We will look first at an analysis of the community as a whole, before focusing on characteristics such as size, budget, discipline, and others.

We collected total budget data for participating organizations and categorized them according to the following scale: $\$ 0-250,000, \$ 250,000$ to 1 million, $\$ 1-5$ million, $\$ 5-10$ million, and over $\$ 10$ million. Most of the organizations have small budgets (371 are in the lowest bracket, less than $\$ 250,000)$. Only 51 organizations have budgets of over $\$ 10$ million. However, these organizations include over half the total staff.

DCLA also groups its grantee organizations into the following disciplines:

- Folk Arts

- Multi-Discipline

- Literature

- $\quad$ New Media

- Zoo

- Dance

- Museum

- Visual Arts
- Architecture/Design

- Botanical

- Humanities

- Music

- Theater

- Film/Visual/Audio

- Photography

- Science

DCLA includes three separate categories under the umbrella multi-discipline term: performing, non-performing, and performing+non-performing. Some disciplines, such as folk arts, science, new media and photography, are very small, each representing fewer than 200 employees among respondents in the DCLA community. Others are much larger, such as dance, museums, multi-discipline, music, and theater. These disciplines include from 2,000 to 10,000 employees each. 


\section{Gender}

\section{Aggregate Measure}

We offered four categories for gender: male, female, does not identify as either male or female, and decline to state. Figure 1 shows the gender composition of responding organizations is $53 \%$ female and $47 \%$ male. This maps almost exactly to the gender composition of New York City based on the 2010 census. ${ }^{7}$

Figure 1: Gender Percentage and Total

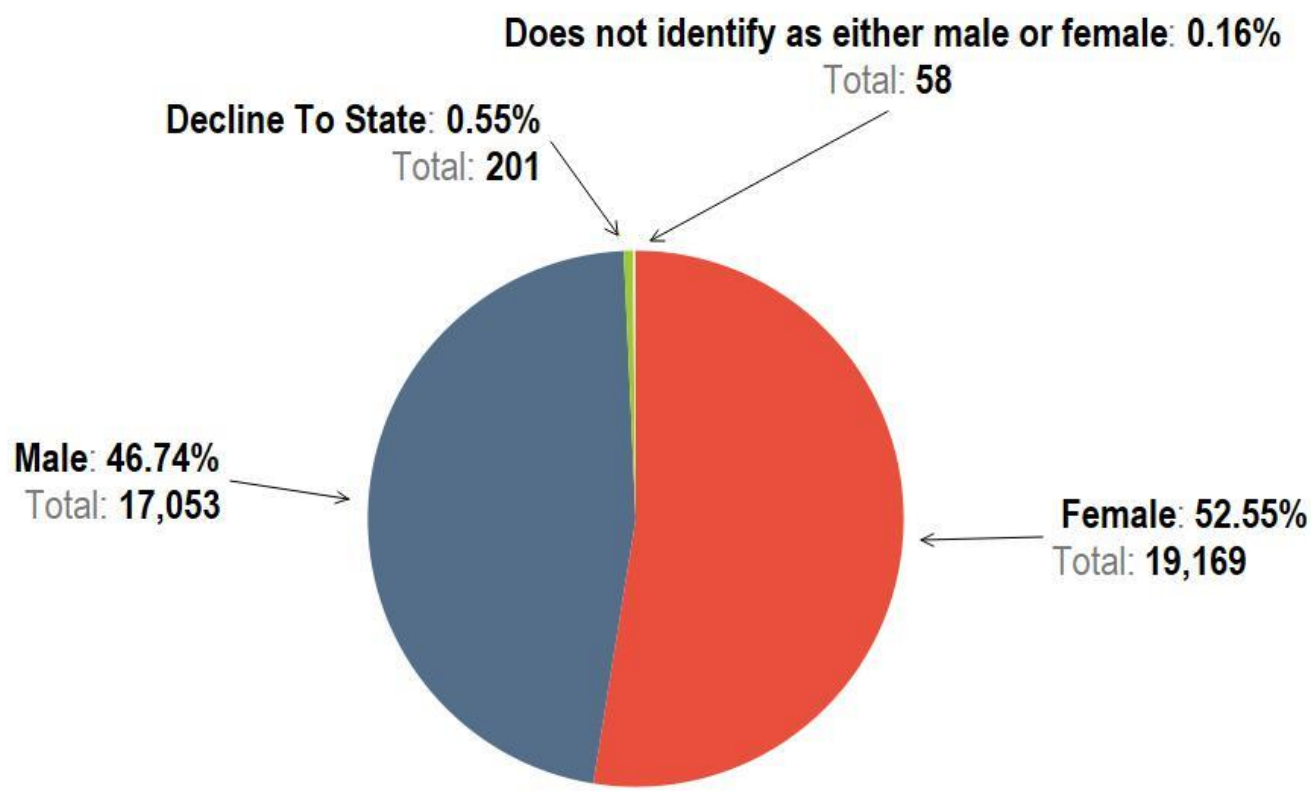

7 "Take Wolfram|Alpha Anywhere..." New York City Percent Female, accessed January 14, 2016, http://www.wolframalpha.com/input/?i=new york city percent female. 
We also collected data on level of seniority. Figure 2 shows that there is a slight pattern as positions move from junior to senior. Female staff compose $52 \%$ of junior positions, $53 \%$ of mid-level positions, and $54 \%$ of senior positions. The size of each pie chart represents the ratio of overall staff in each category.

Figure 2: Gender by Level of Seniority

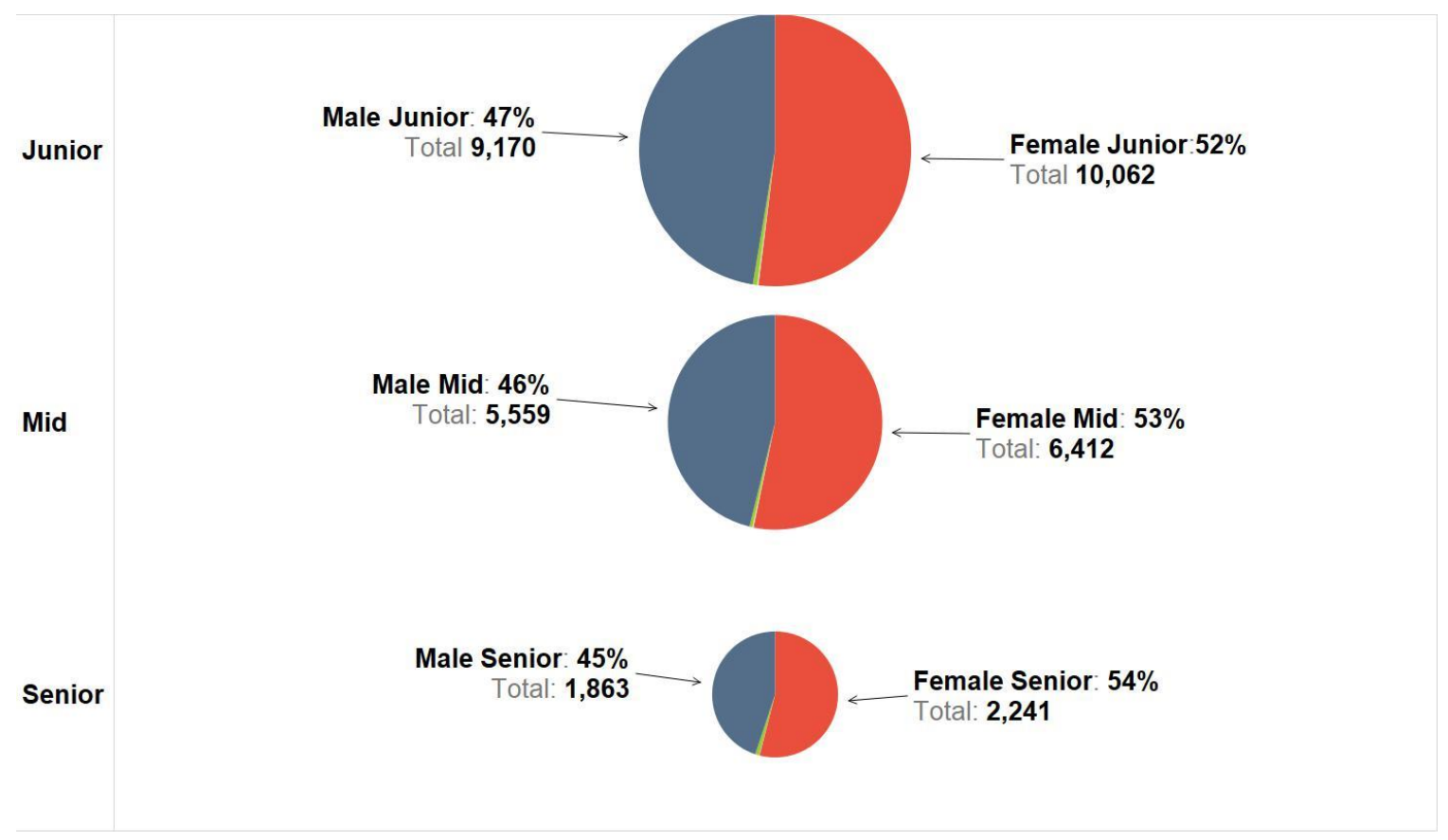


In Figure 3, we see an organizational distribution by gender. Each column represents an aggregation of organizations with a given percentage of female staff. The graph forms a rough bell curve. One hundred and fifty four organizations have $50 \%$ female staff. Twenty-seven organizations are $100 \%$ female. Seven organizations are $0 \%$ female.

Figure 3: Organizational Distribution by Gender

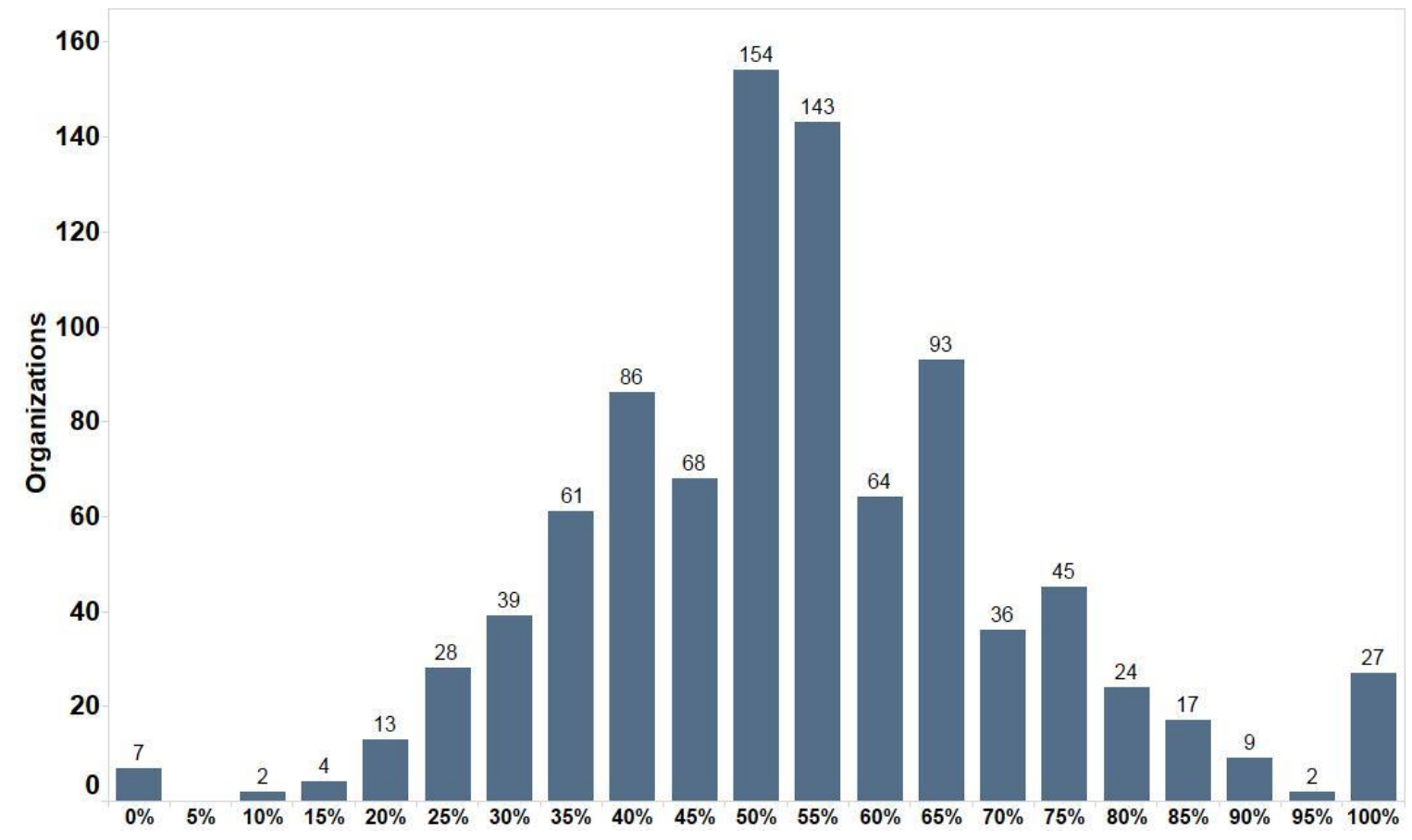




\section{Budget}

DCLA provided us with the budget categories they use internally by the department for reporting. Using these budget categories, we analyzed the demographics of staff employed in each group. In Figure 4, the top graph shows the total number of staff in each category. The bottom graph shows the percentage of female staff in that total. We found that organizations with budgets over $\$ 10$ million have on average 6-9\% more male employees than any other budget category.

Figure 4: Budget: Totals and Percent Female

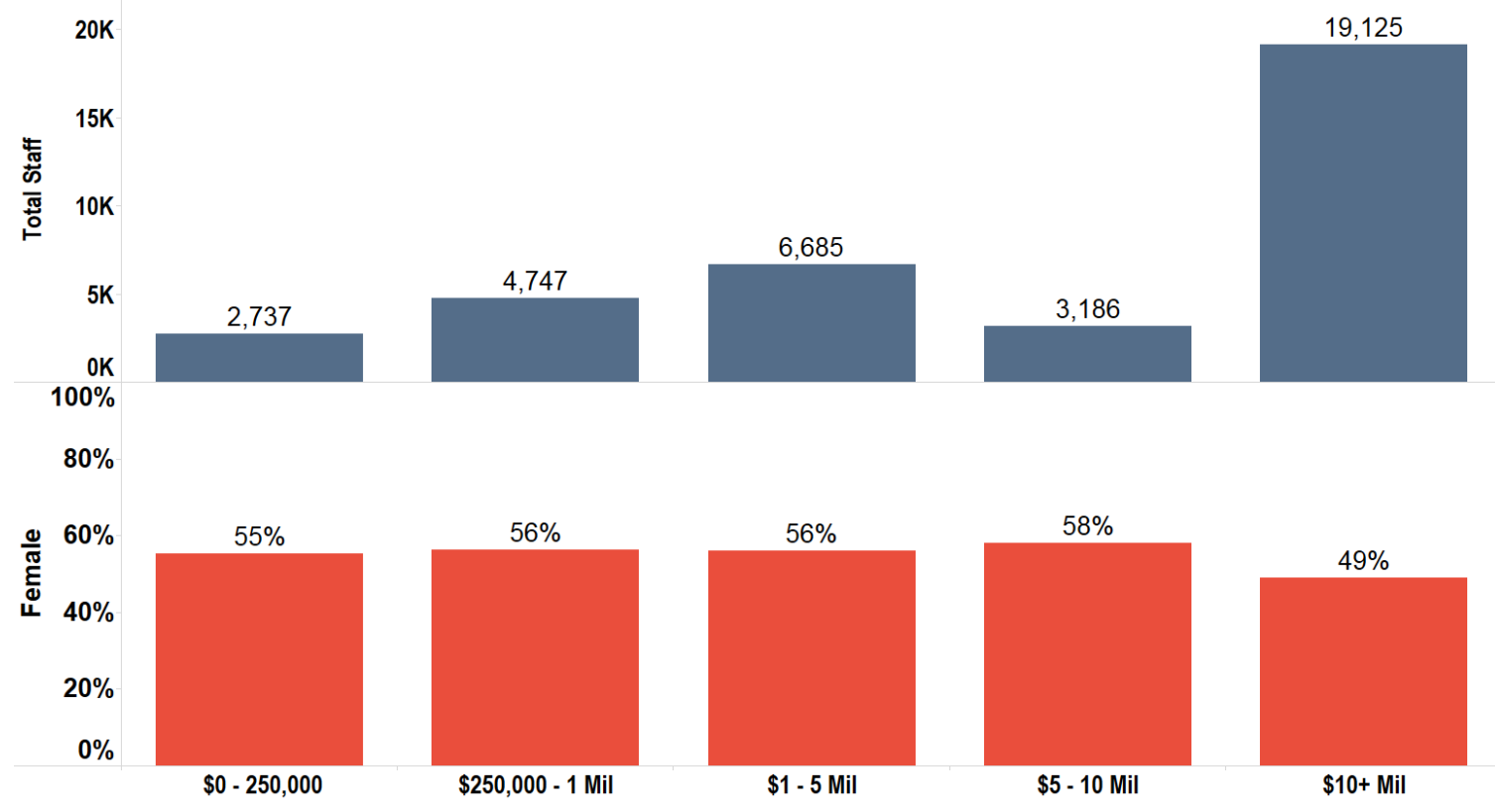

As positions in the $\$ 10+$ category move from junior to senior, the percentage female increases: $48 \%$ in junior positions, $50 \%$ in mid positions, $52 \%$ in senior positions. In smaller budget categories we find the opposite trend. The percentage female decreases slightly across other budget categories as positions move from junior to senior. 


\section{Discipline}

We also used discipline categories provided by DCLA. Figure 5 shows the total number of employees in a given discipline compared to the percentage of female employees in those disciplines.

Figure 5: Discipline: Totals and Percent Female

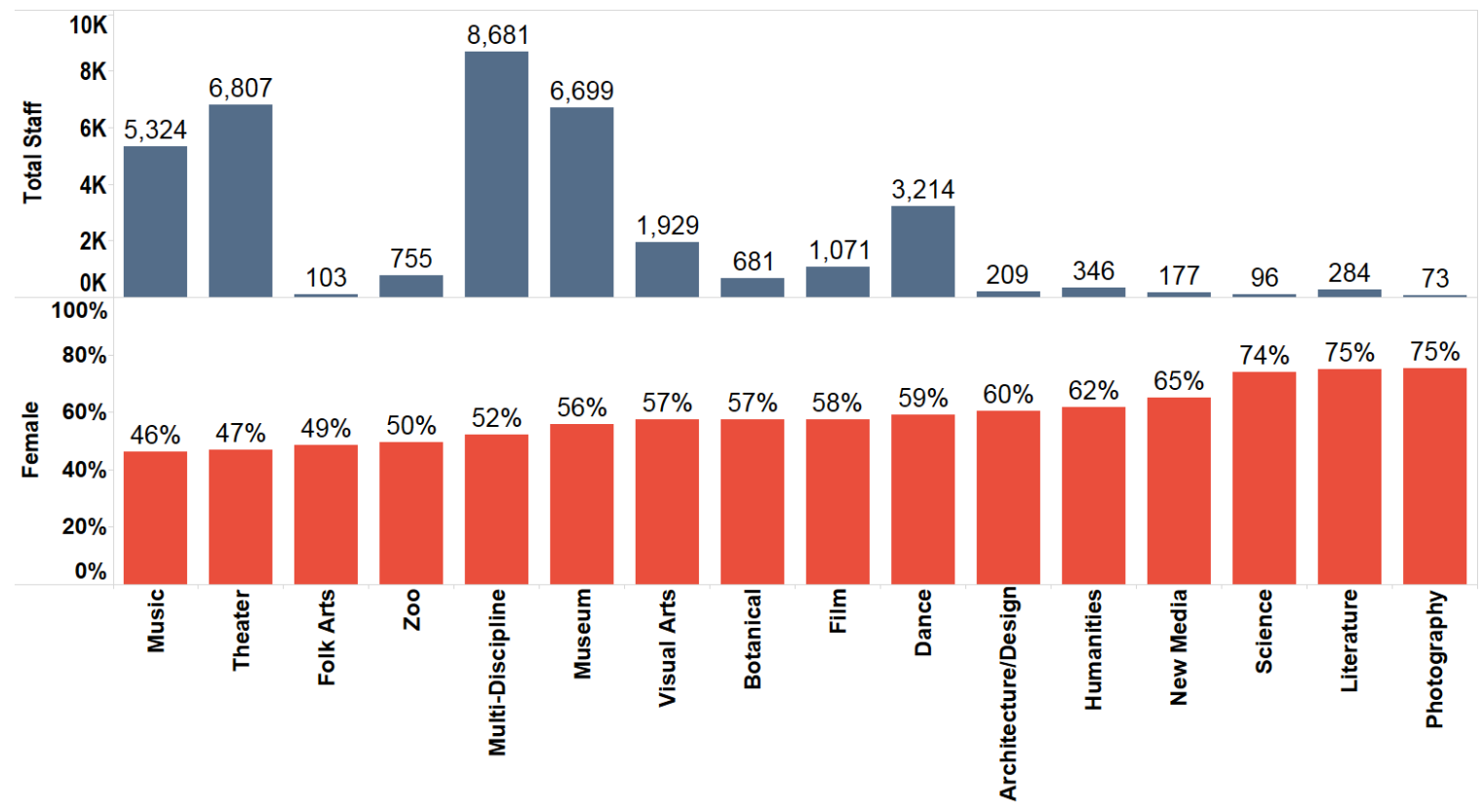

We can see there is a wide range in size of discipline. Music and theater are grouped together to the left of the graph at $46 \%$ and $47 \%$ female. Of the larger disciplines, dance has the highest percentage of women at $59 \%$. Museums are $56 \%$ and multi-discipline organizations are $52 \%$ female.

\section{Job Type}

Based on the 22 job categories we developed with guidance from DCLA, along with level of seniority, we gained a rich picture of a) the race/ethnicity and gender breakdown of each position, b) the number of employees in each role, c) the degree of demographic variance between levels of seniority in those positions. 
Figure 6 analyzes these job types. The top graph shows the total number of employees in a job type, while the bottom graph measures the percentage female. This graph includes board members and volunteers.

Figure 6: Job Type: Totals and Percent Female
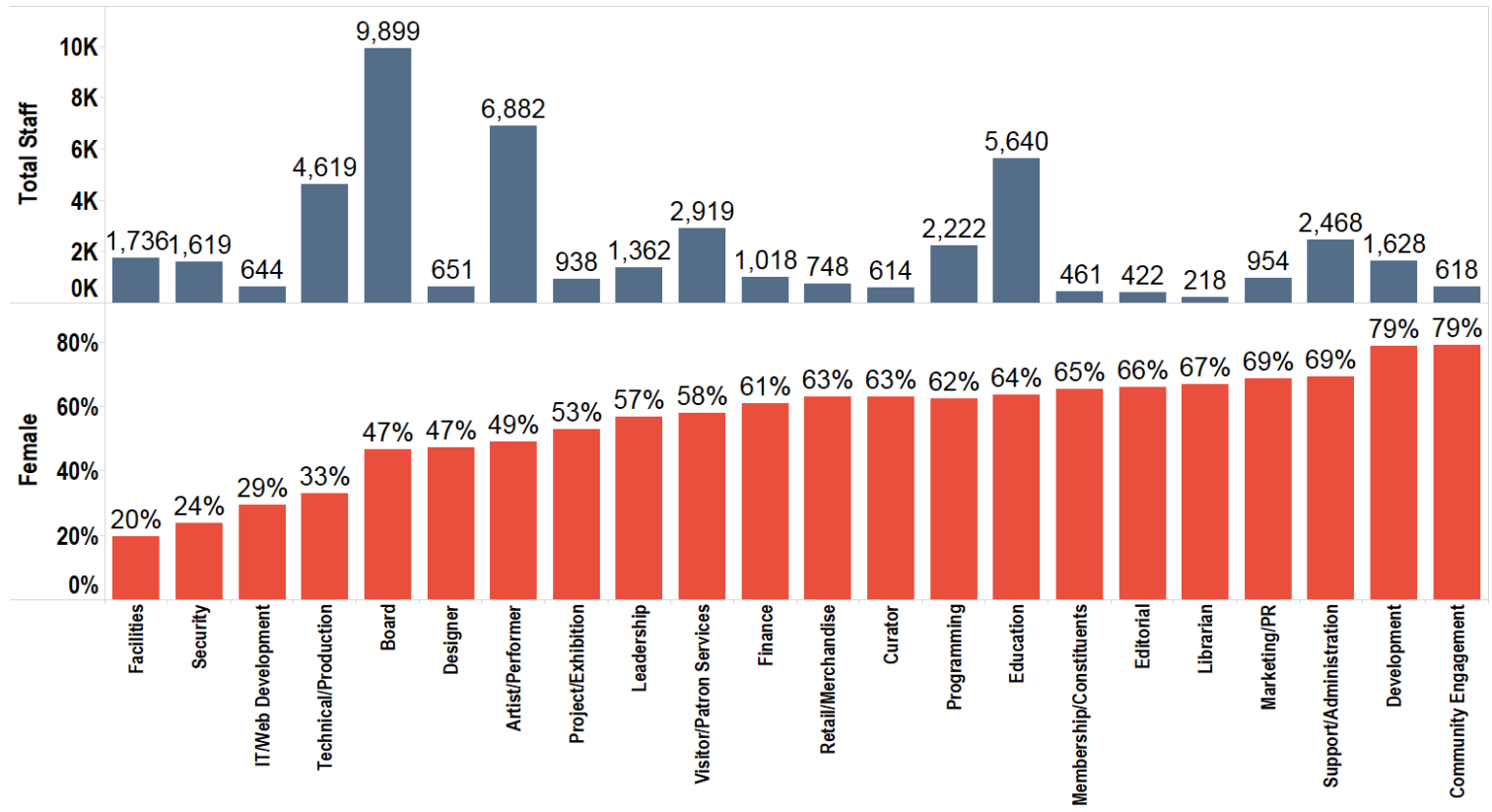

Again, we see there is a wide range of the number of staff in each job type, from just over 200 librarians (mostly in museums) to just under 7,000 artists/performers in DCLA funded organizations, distributed mainly across the larger disciplines. Community engagement and development have the highest percentage of female employees at $79 \%$. Security and facilities are the least female, with $24 \%$ and $20 \%$ female staff, respectively. Technical/production, a relatively large job type, is 33\% female. Educators are $64 \%$ female. Artist/performers are 49\%. Leadership positions are 10 percentage points higher than board positions. 
Figure 7 shows the totals and percent female for leadership positions in the large disciplines. We see that dance, museum, and multi-discipline organizations are between $58 \%$ and $63 \%$ female. Theater is $51 \%$ and music is $45 \%$ female.

Figure 7: Leadership by Gender Totals and Percent Large Disciplines

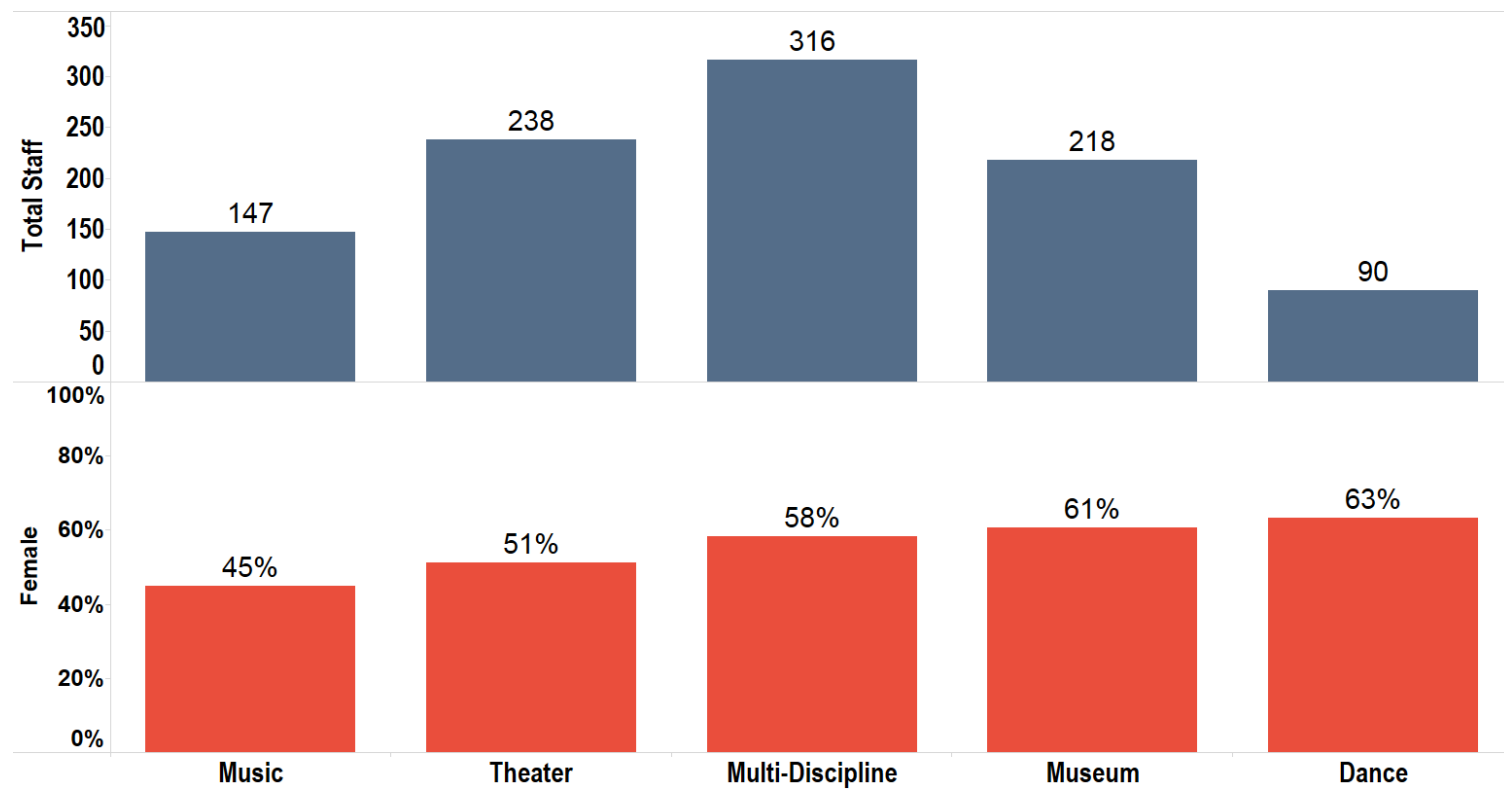


Figure 8 shows the totals and percent female for board members in the large disciplines. Dance is the only discipline above $50 \%$. Multi-Discipline has the most board members $(2,266)$ and the fewest female board members $(43 \%)$.

Figure 8: Board by Gender Totals and Percent Large Disciplines

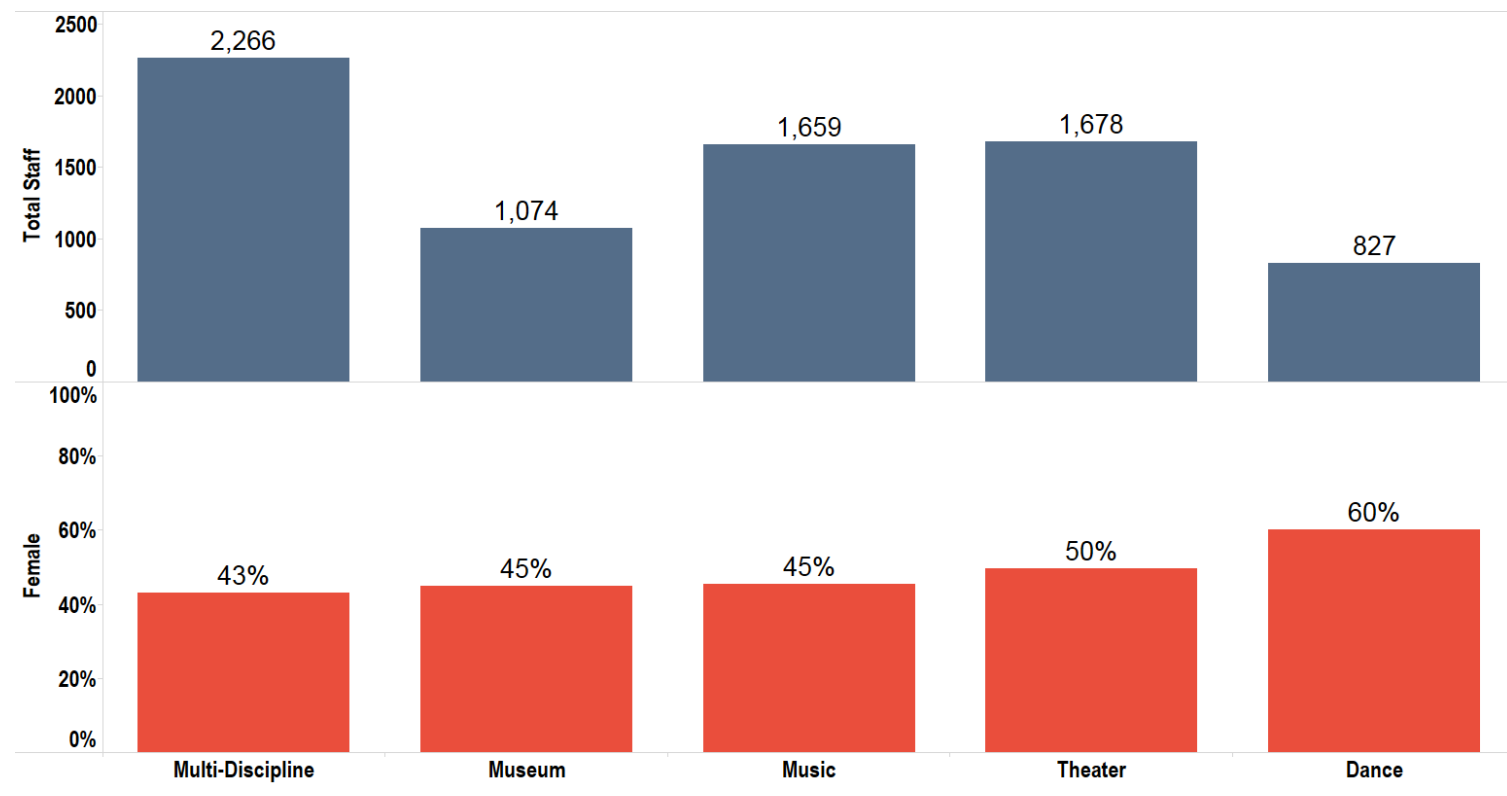


Figure 9 shows the totals and percentage female staff for technical/production positions in large disciplines. We see that for museum and dance percentages are over $40 \%$, but for the theater and music disciplines technical/production staff are under $30 \%$ female.

Figure 9: Technical/Production by Gender Totals and Percent Large Disciplines

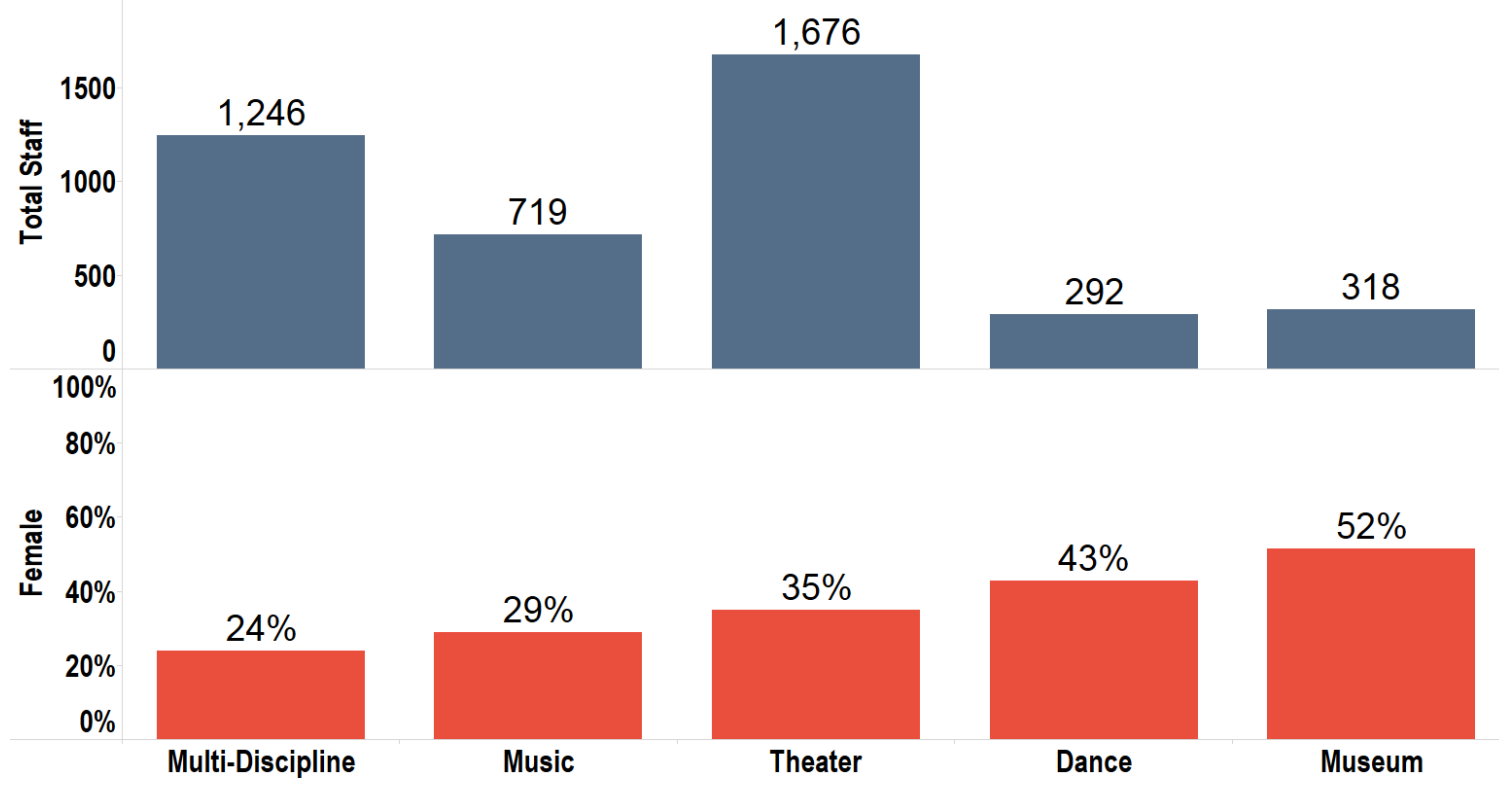




\section{Decade Born and Decade Hired}

Because this is the only year this survey has been conducted, longitudinal analysis is not possible. Some inferences toward temporal trends can be made by looking at the most common age-groups of DCLA employees, as well as the decade most employees were hired. However, these are not conclusive trends.

Figure 10 shows the total number of employees born in a given decade in relation to the percentage of female employees born in that decade.

Figure 10: Decade Born Total Staff and Percentage Female

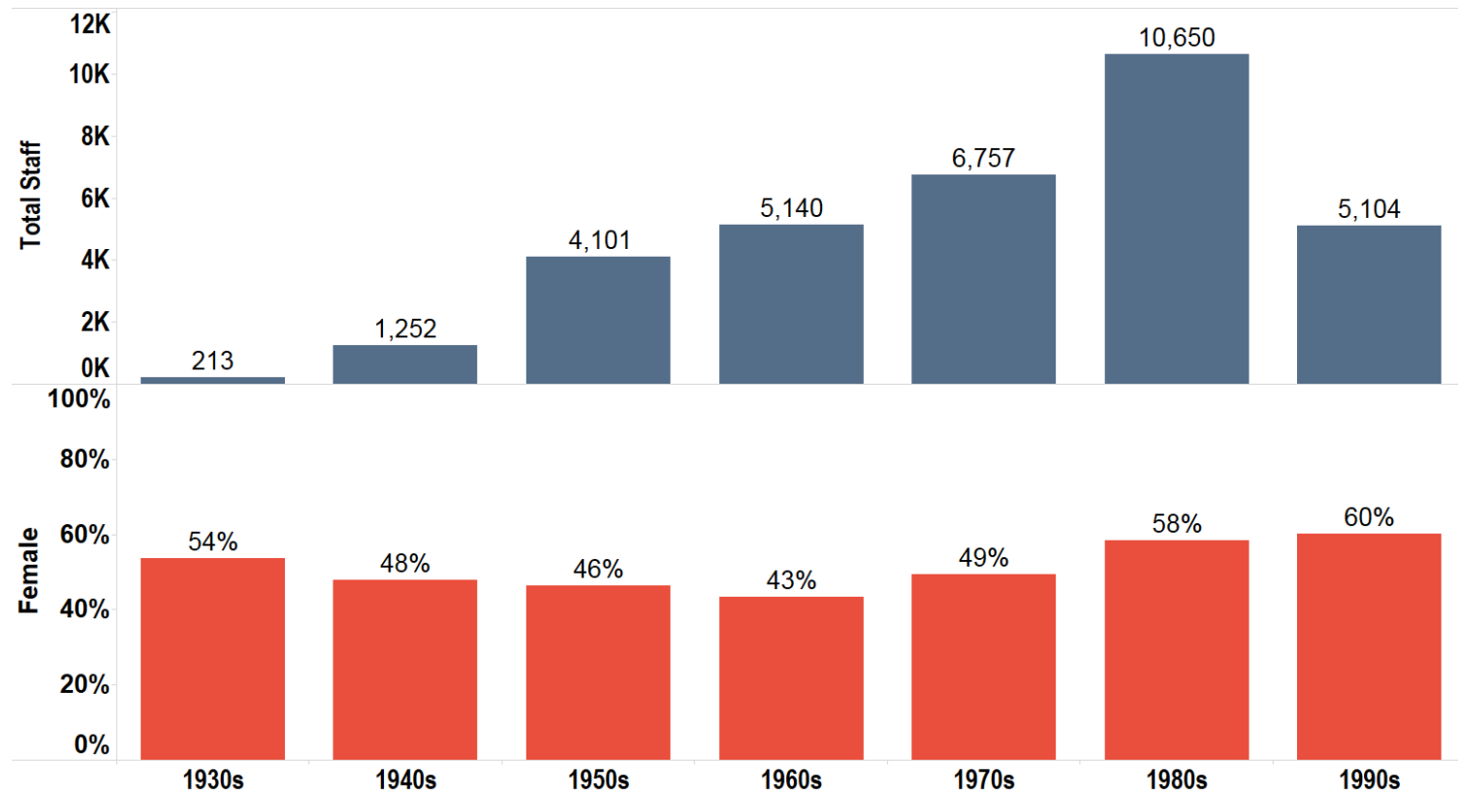

A plurality of staff were born in the 1980 s. We can also see from this graph that younger staff are more female. 
Figure 11 shows the total number of employees hired in a given decade, in relation to the percentage of female employees hired in that decade.

Figure 11: Decade Hired: Total Staff and Percentage Female

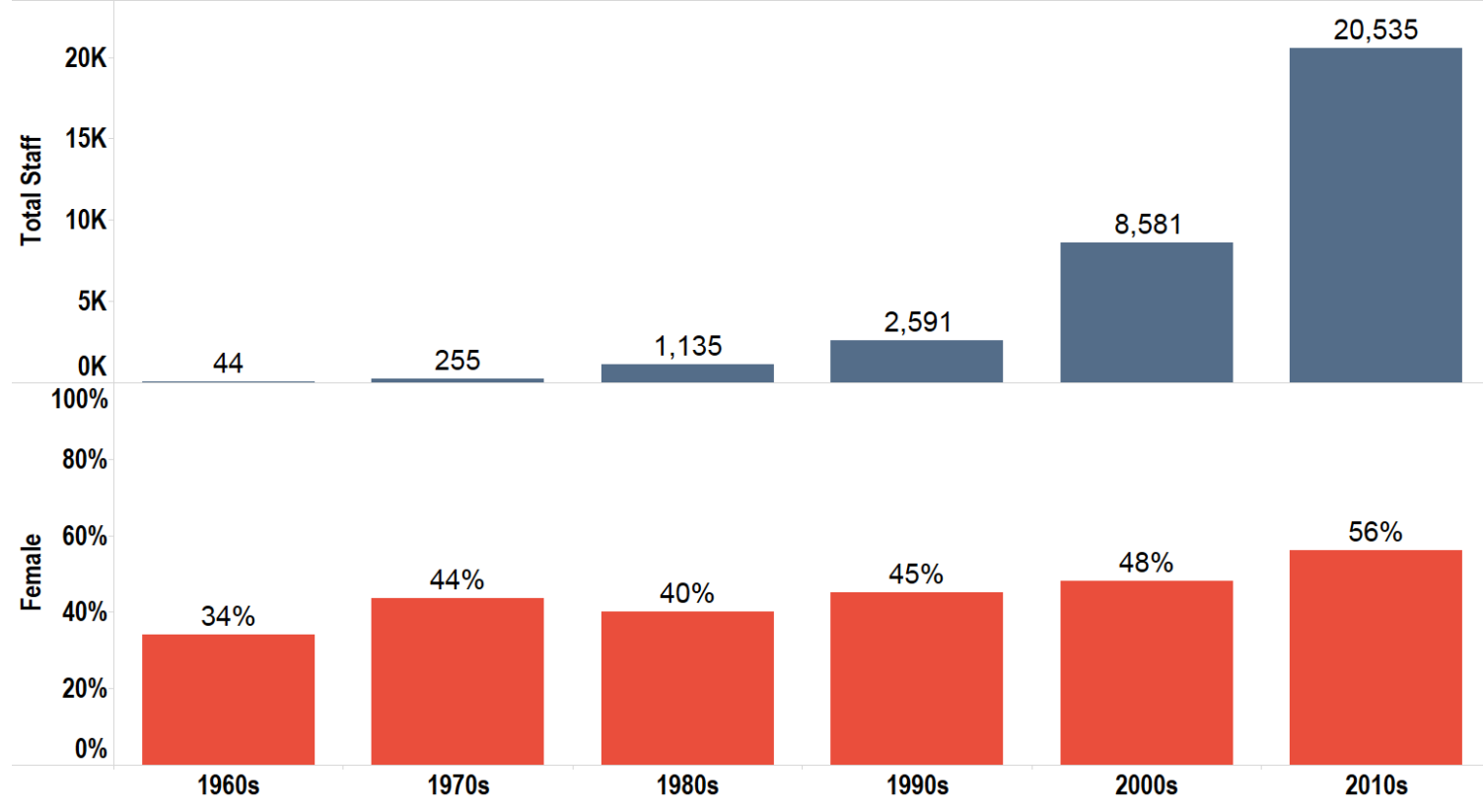

The majority of staff currently working at DCLA funded cultural organizations were hired in the last 6 years. That group is also the most female, $56 \%$. 


\section{Volunteers}

Figure 12 shows Volunteers by Gender. Volunteers are 65\% female, 35\% male. That percentage remains relatively consistent across decade of birth.

Figure 12: Volunteers Gender Pie

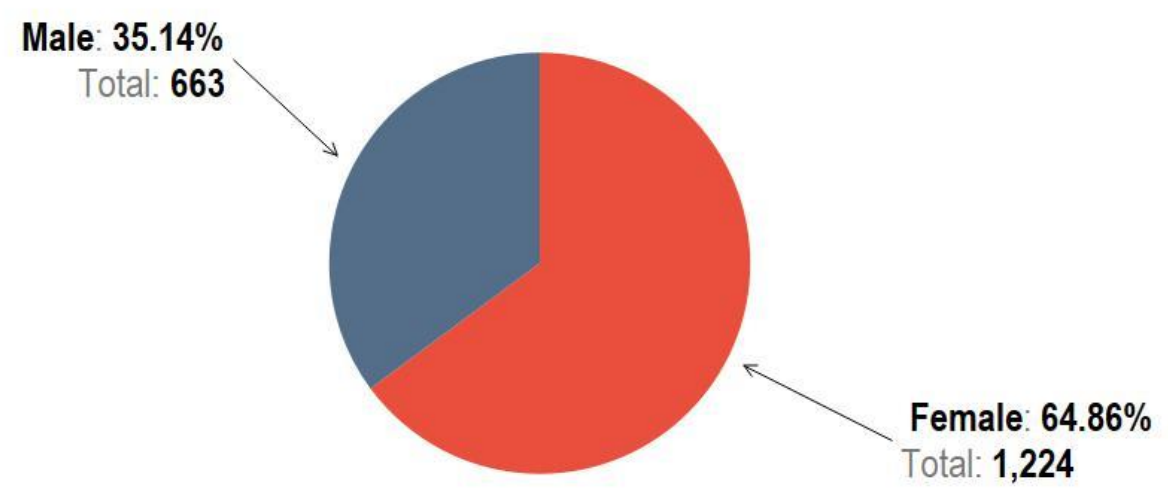




\section{Race/Ethnicity}

\section{Aggregate Measure}

In the aggregate, DCLA staff is $62 \%$ white non-Hispanic and $38 \%$ minority, as shown in Figure 13. Minority groups with over five percent representation include black or African American (15\%), Hispanic (10\%) and Asian (8\%). White non-Hispanic staff are 17 percentage points above the average population for New York City, based on the 2010 census. $^{8}$

Figure 13: Race/Ethnicity Staff Percentages

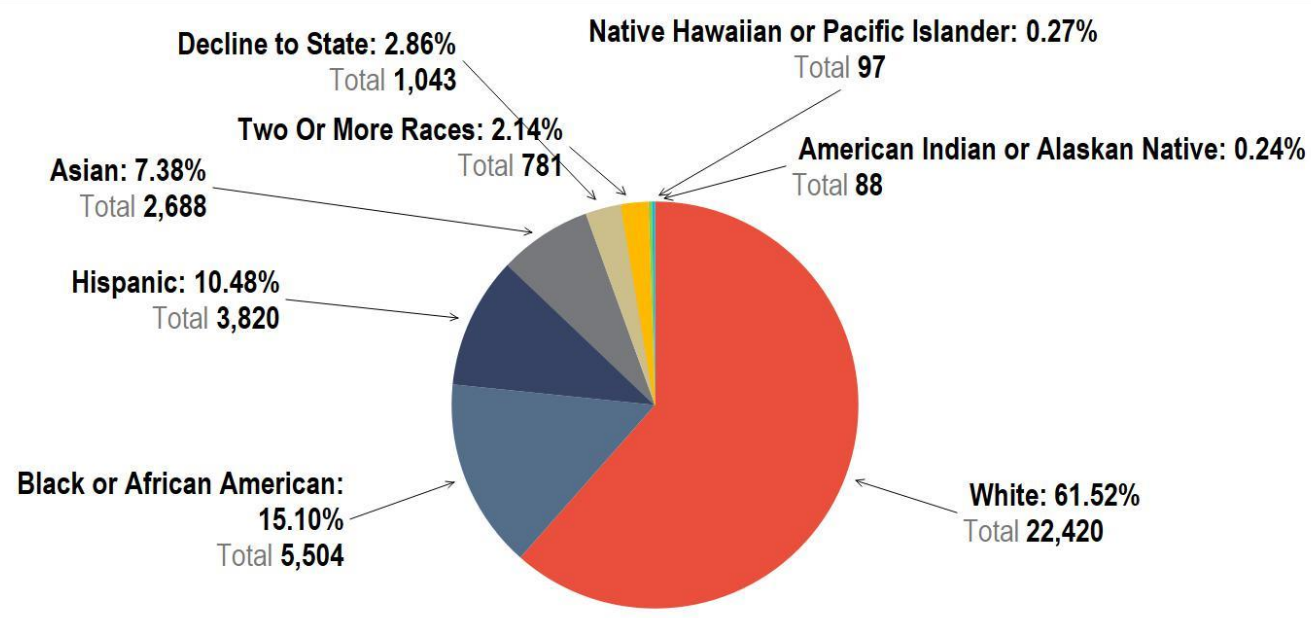

8 "Take Wolfram|Alpha Anywhere..." New York City White Alone, accessed January 13, 2016, http://www.wolframalpha.com/input/?i=New York City white alone\&lk=1. 
As positions move from junior to senior the total number of staff shrinks. Notice in Figure 14 how the bars representing minorities flatten out from left to right. Positions become significantly more white non-Hispanic as they become more senior: $55 \%$ are in junior positons, $68 \%$ in mid-level positions, and $74 \%$ in senior roles.

Figure 14: Total Staff by Race/Ethnicity Separated by Level of Seniority

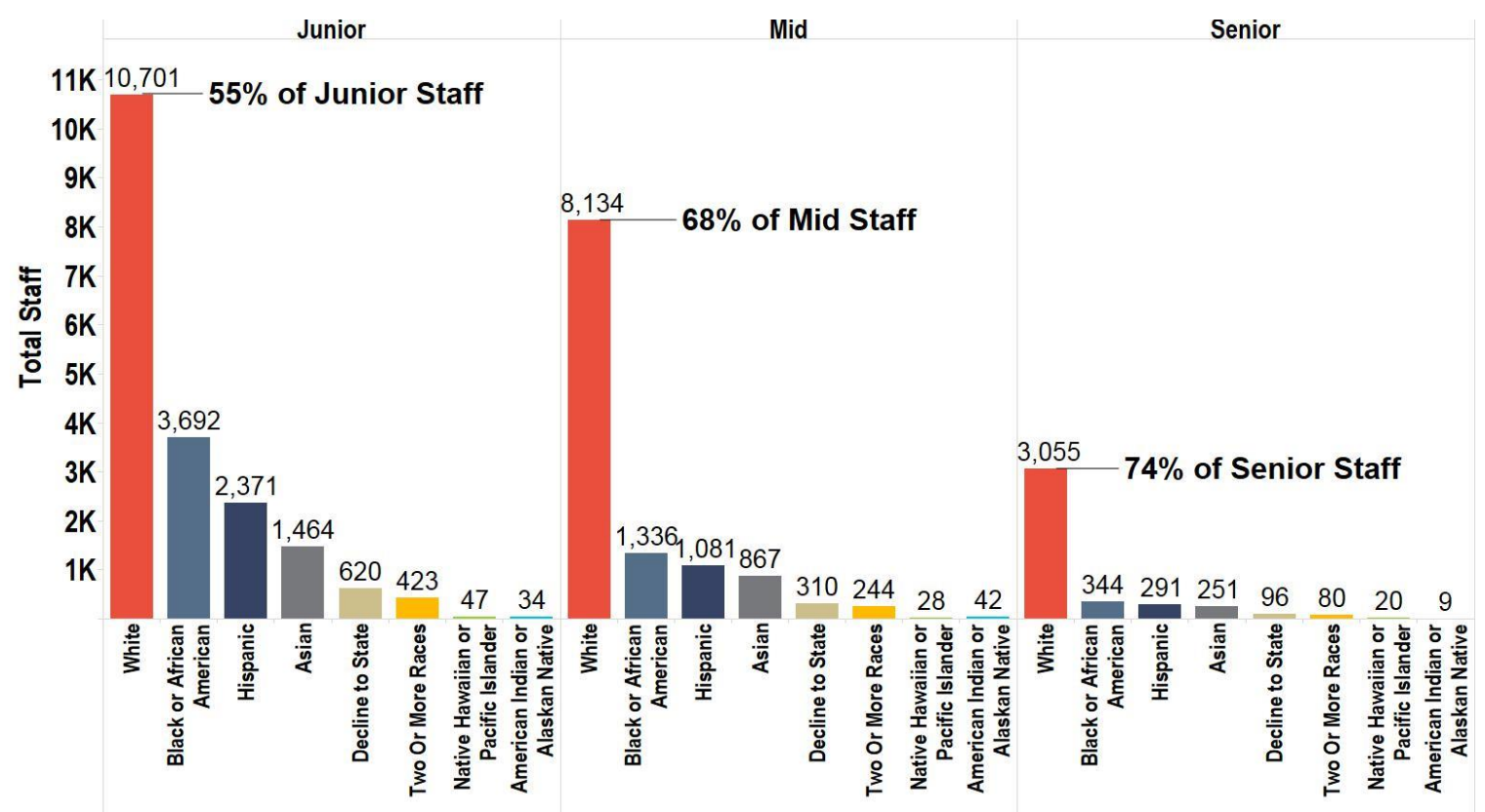


Figure 15 shows an organizational distribution based on the percentage white nonHispanic staff. Each column represents an aggregation of organizations that have a given percentage of white non-Hispanic staff. A plurality of these organizations (93) are 80\% white non-Hispanic. There are 73 institutions that are $100 \%$ minority and 82 institutions that are $100 \%$ white non-Hispanic, as seen on the far right and far left of the graph. Many of the entirely minority organizations have a specific ethnic focus.

Figure 15: Race/Ethnicity Histogram

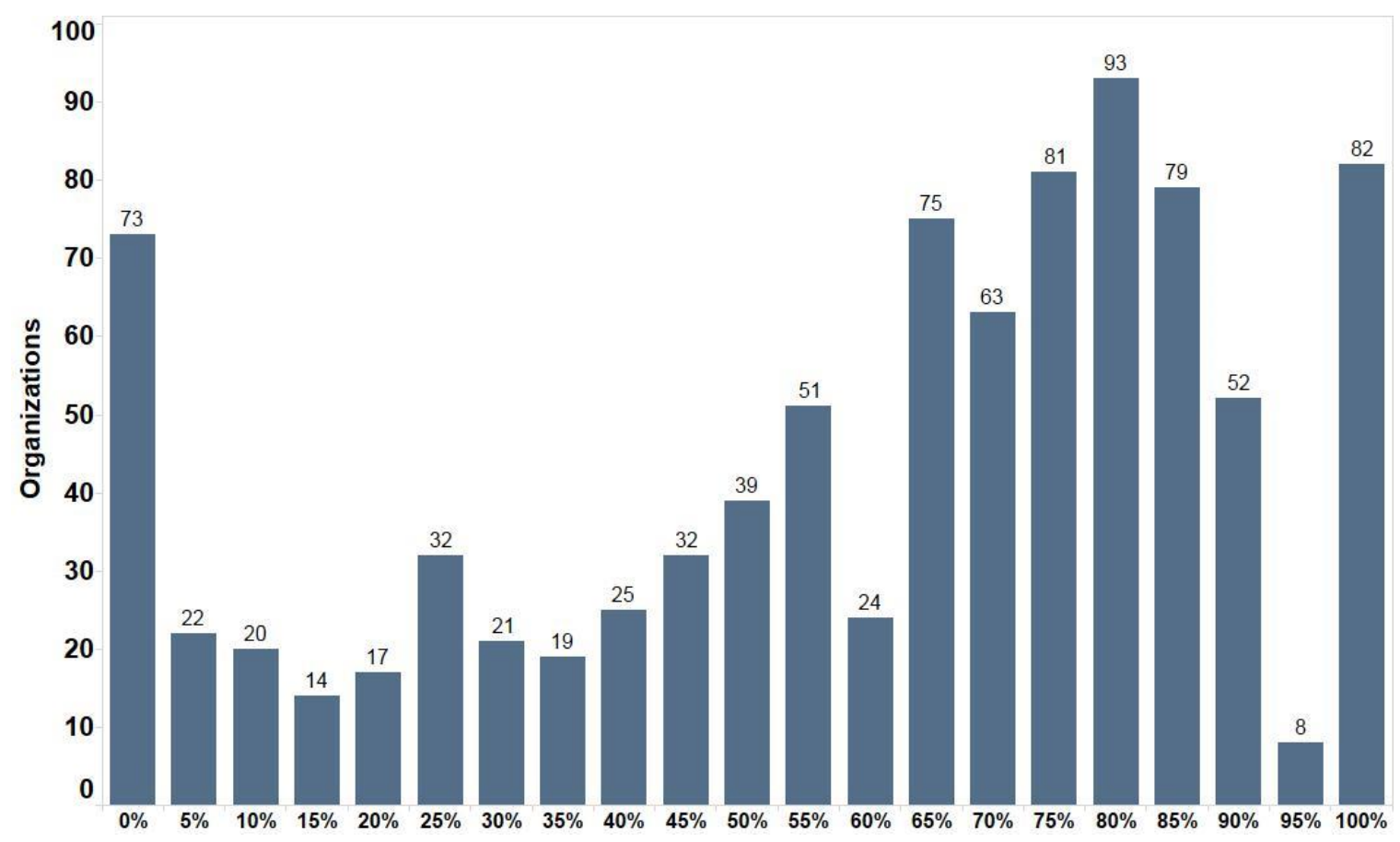




\section{Budget}

Analyzing staff diversity by budget reveals several clear patterns. As an organization's budget increases so does its percent of white non-Hispanic employees. Figure 16 shows the relationship between the staff totals for each budget category, and the percentage of white non-Hispanic employees within those categories.

Figure 16: Budget Totals and Percentage White Non-Hispanic

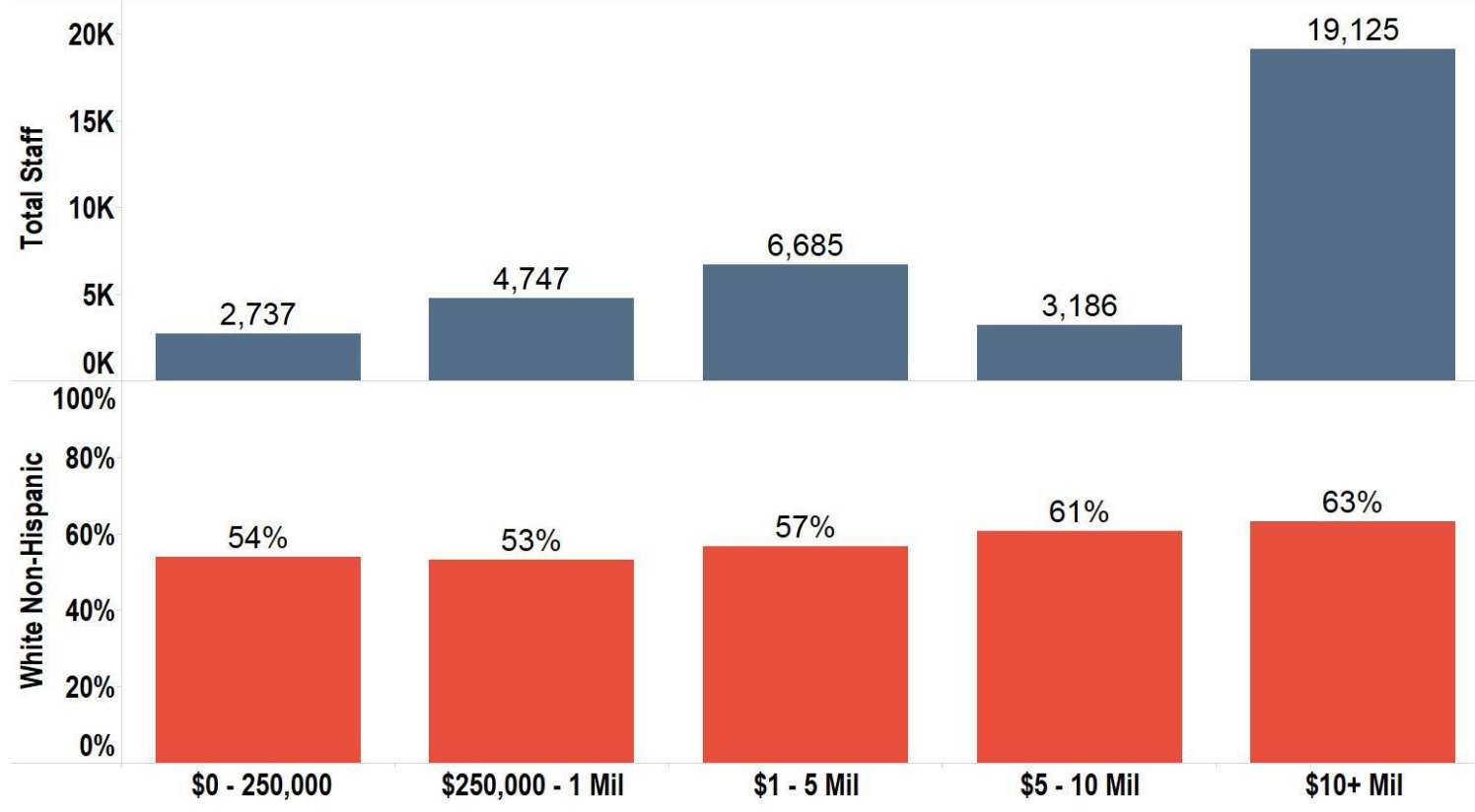

This graph reveals that organizations with less than $\$ 250,000$ dollar budgets hire on average 10 percentage points more minority employees than organizations with over $\$ 10$ million budgets. The curve appears gradual as a percentage, but if considered along with the totals we can see that those small percentages can increase total employees by an order of magnitude.

For instance, organizations with budgets of over $\$ 10$ million have only 2 percentage points more white non-Hispanic employees than organizations with $\$ 5$ - $\$ 10$ million budgets. There are 10,418 more white non-Hispanic staff working at $\$ 10+$ million organizations. The difference in white non-Hispanic employees between the \$250,000-1 million and $\$ 1-5$ million budget categories is also $2 \%$, but the difference in total white non-Hispanic staff is only 1,103 . 


\section{Discipline}

Figure 17 shows the relationship that exists between total employees in a given discipline and the percentage of white non-Hispanic employees in that discipline.

Figure 17: Discipline Totals and Percentage White Non-Hispanic

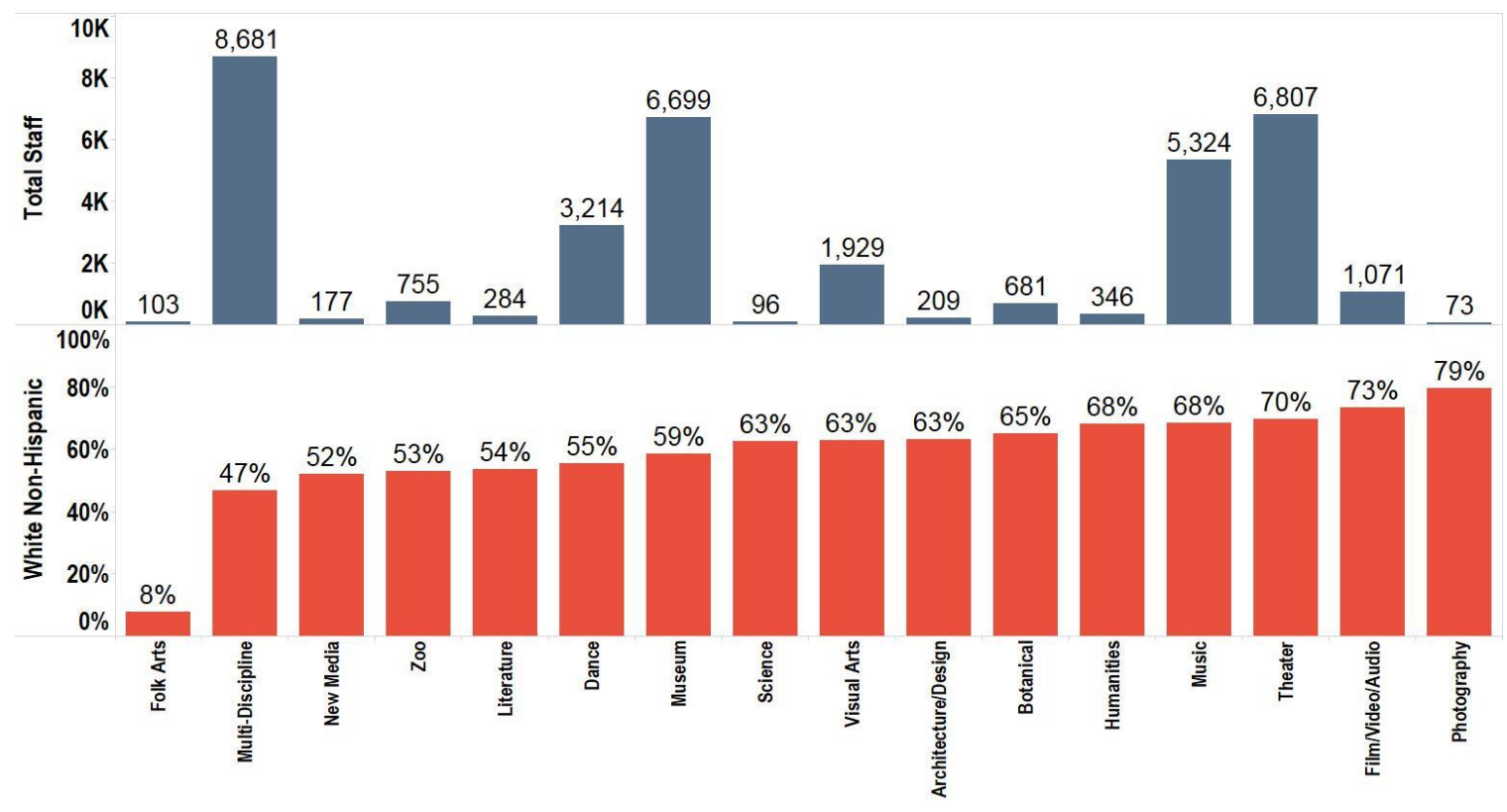

Of the larger disciplines, theater and music employ the most white non-Hispanic staff at $70 \%$ and $69 \%$, respectively. The category multi-discipline hovers just under 50\% white non-Hispanic staff. 


\section{Job Type}

In Figure 18 we see a pair of bar graphs showing the relationship between total number of employees within a job category and the percentage of white non-Hispanic employees in that category. This graph includes board members and volunteers.

Figure 18: Job Type Totals and Percentage White Non-Hispanic

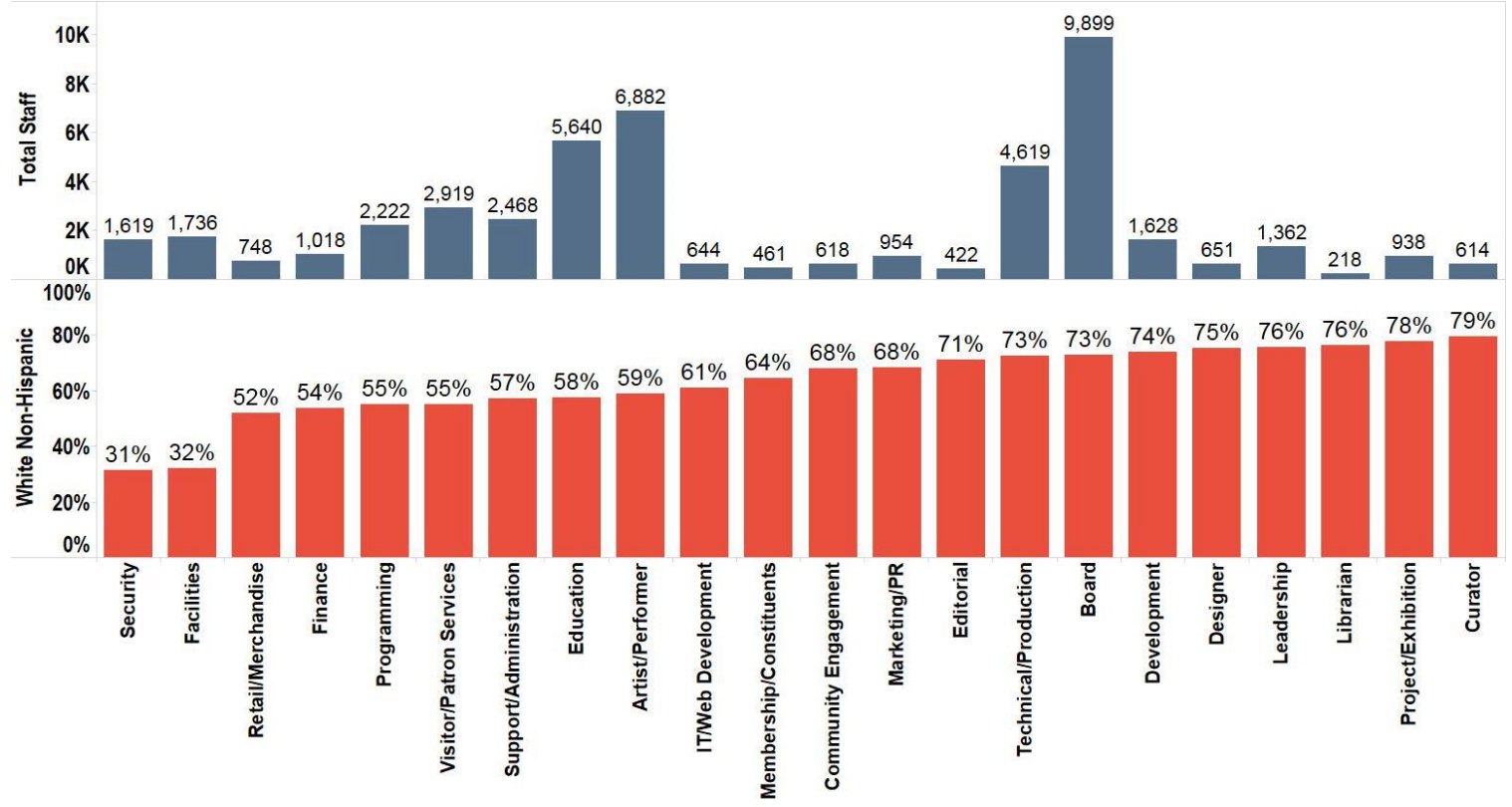

Of the job types with over 1000 staff, three clusters emerge. Security and facilities are grouped together at $31 \%$ and $32 \%$ white non-Hispanic staff. This tracks with what we found in the North American museum community.

Then there is a cluster of positions that range between $54 \%$ and $59 \%$. These positions include: finance, programming, visitor/patron services, support/administration, education, and artist/performer.

The third cluster of large job types ranges between $73 \%$ and $76 \%$. These positions include: technical/production, board, development, and leadership. 
Figure 19 shows some more detail on the racial composition of leadership positions. Black or African American staff make up 9\% of leadership staff. Hispanic staff are 5\% and Asian staff are 4\%.

Figure 19: Leadership Race/Ethnicity

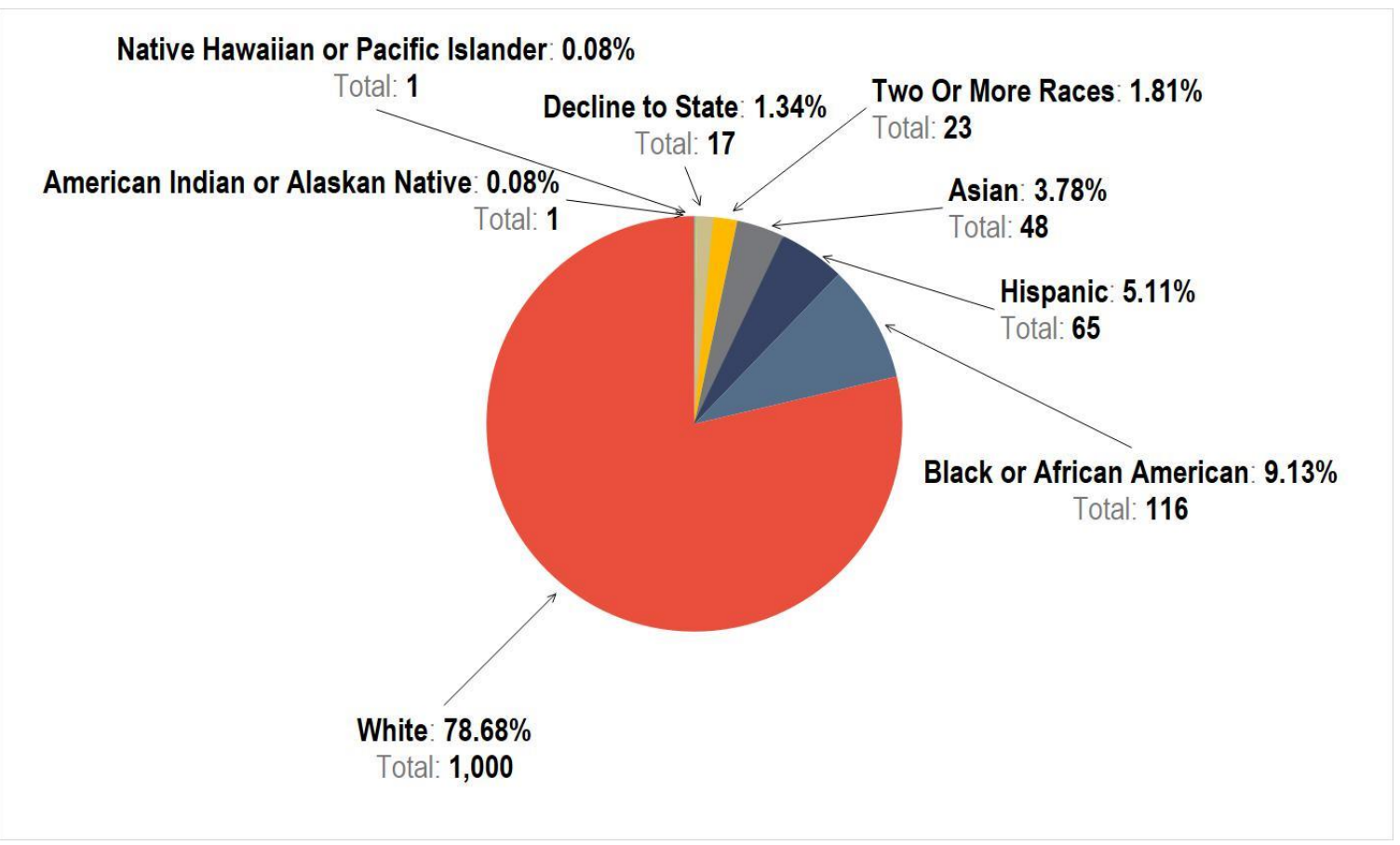


Although there is a 10 percentage point difference in board and leadership positions by gender, Figure 20 shows that racially the differences are fairly minor.

Figure 20 Board Race/Ethnicity

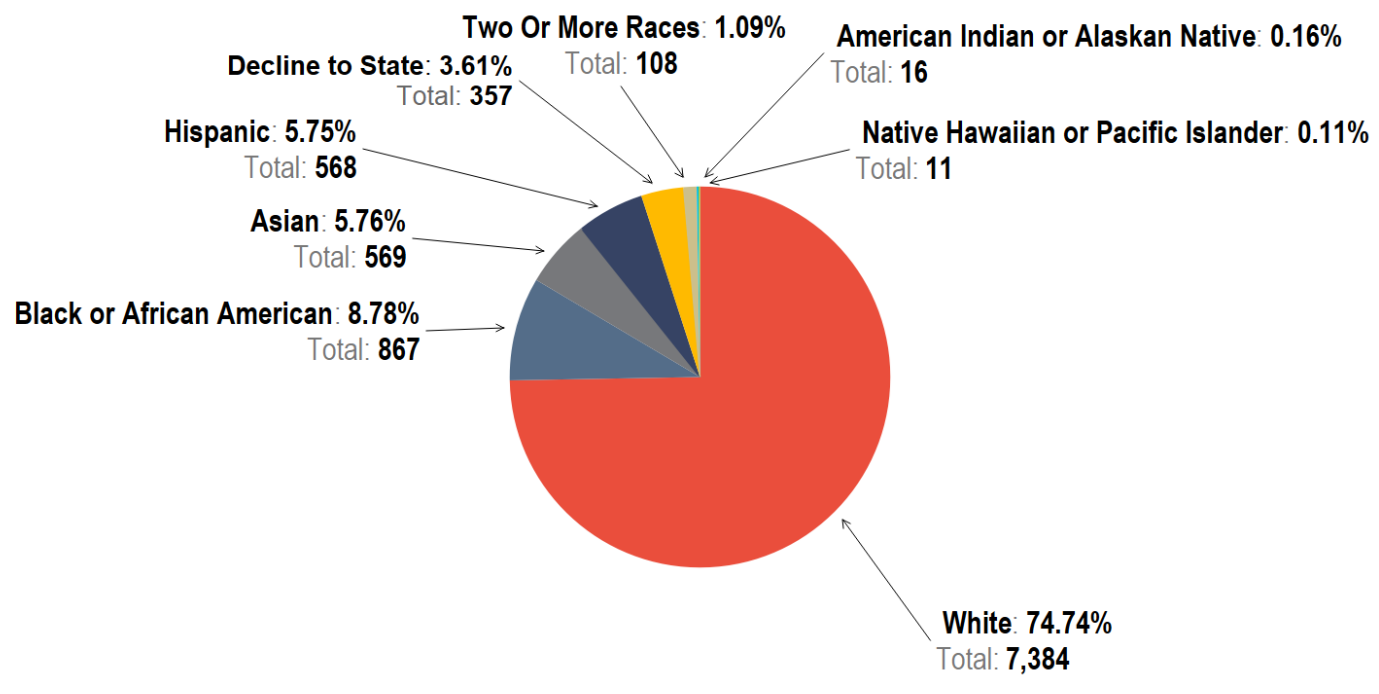


Figure 21 shows total leadership staff, as well as percent white non-Hispanic for large disciplines. Museums have a high number of staff categorized as leadership (219) and have the highest percent white non-Hispanic staff of the large disciplines (85\%). This percentage aligns with what we found in the North American museum community in an earlier staff diversity study.

Figure 21: Leadership Race/Ethnicity Totals and Percent Large Disciplines

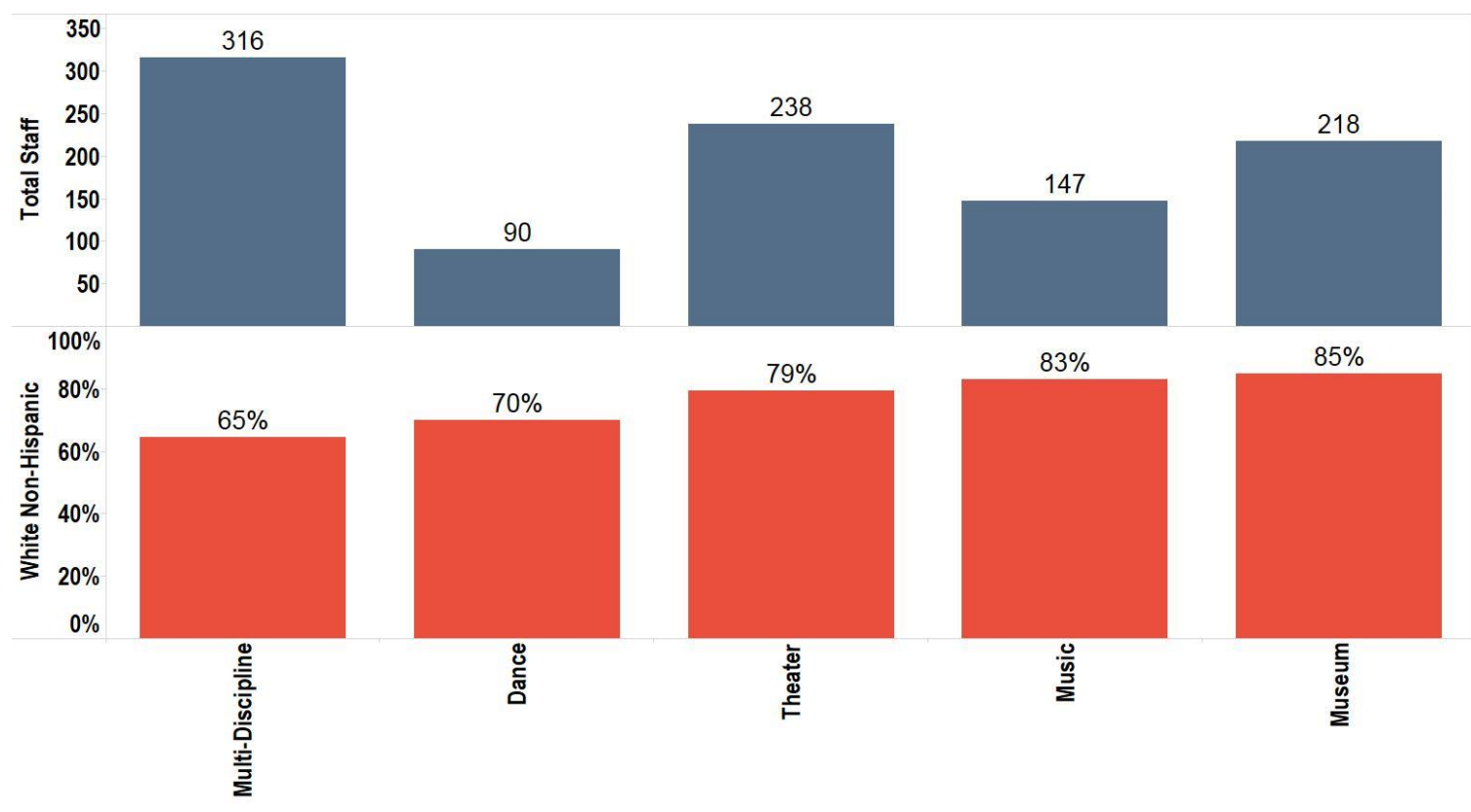


Figure 22 shows that boards are slightly less white non-Hispanic in the large disciplines. Dance is the exception, increasing from $70 \%$ white non-Hispanic leadership to $73 \%$ for board members.

Figure 22: Board Race/Ethnicity Totals and Percent Large Disciplines

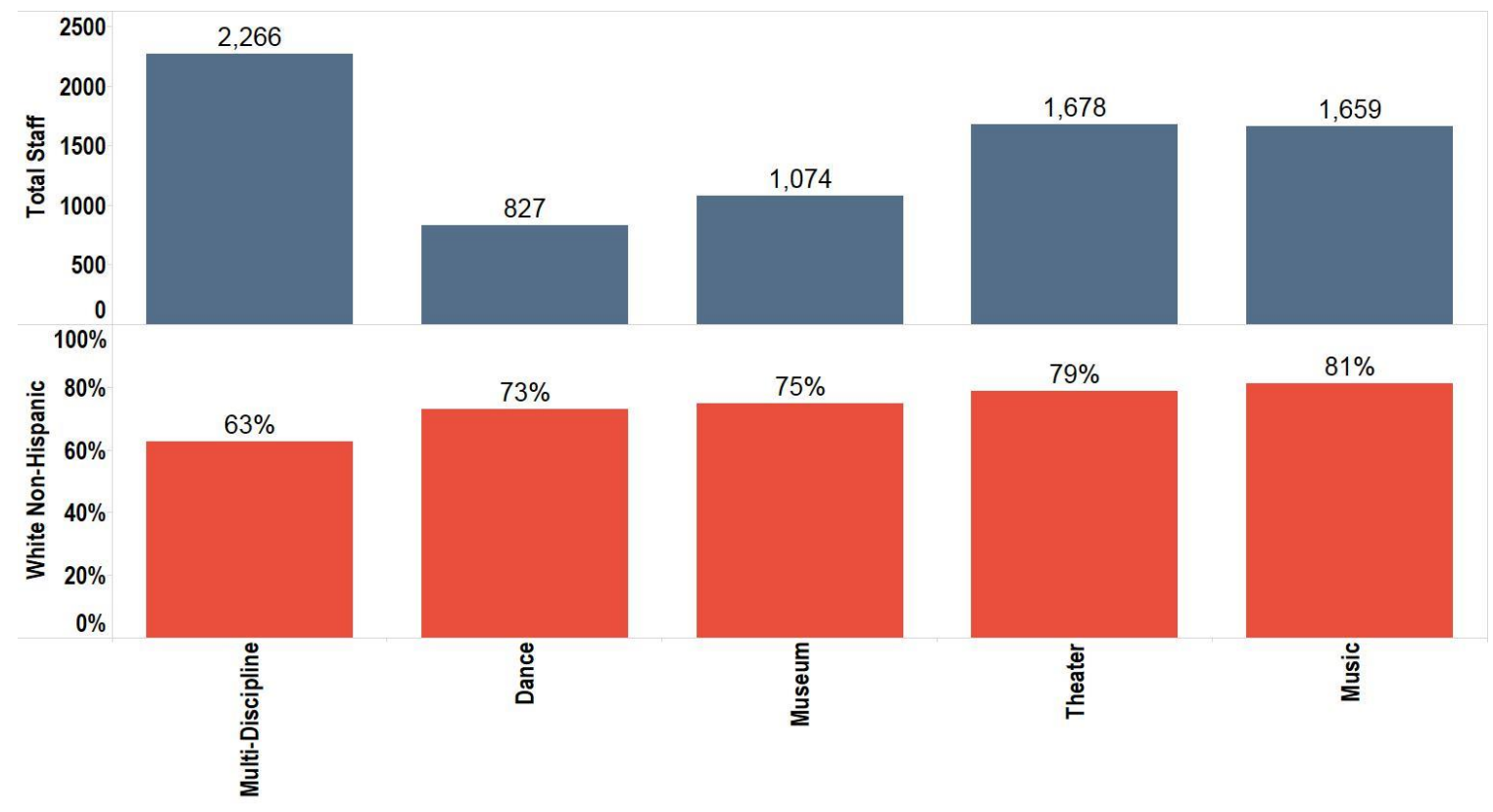


Figure 23 shows positions in theater that are over three quarters white non-Hispanic. The graph shows that, among this cluster, there are four times more technical/production staff than in the next most common job type. Approximately the same is true of the music discipline.

Figure 23: Theater Job Categories over 75 \% White Non-Hispanic

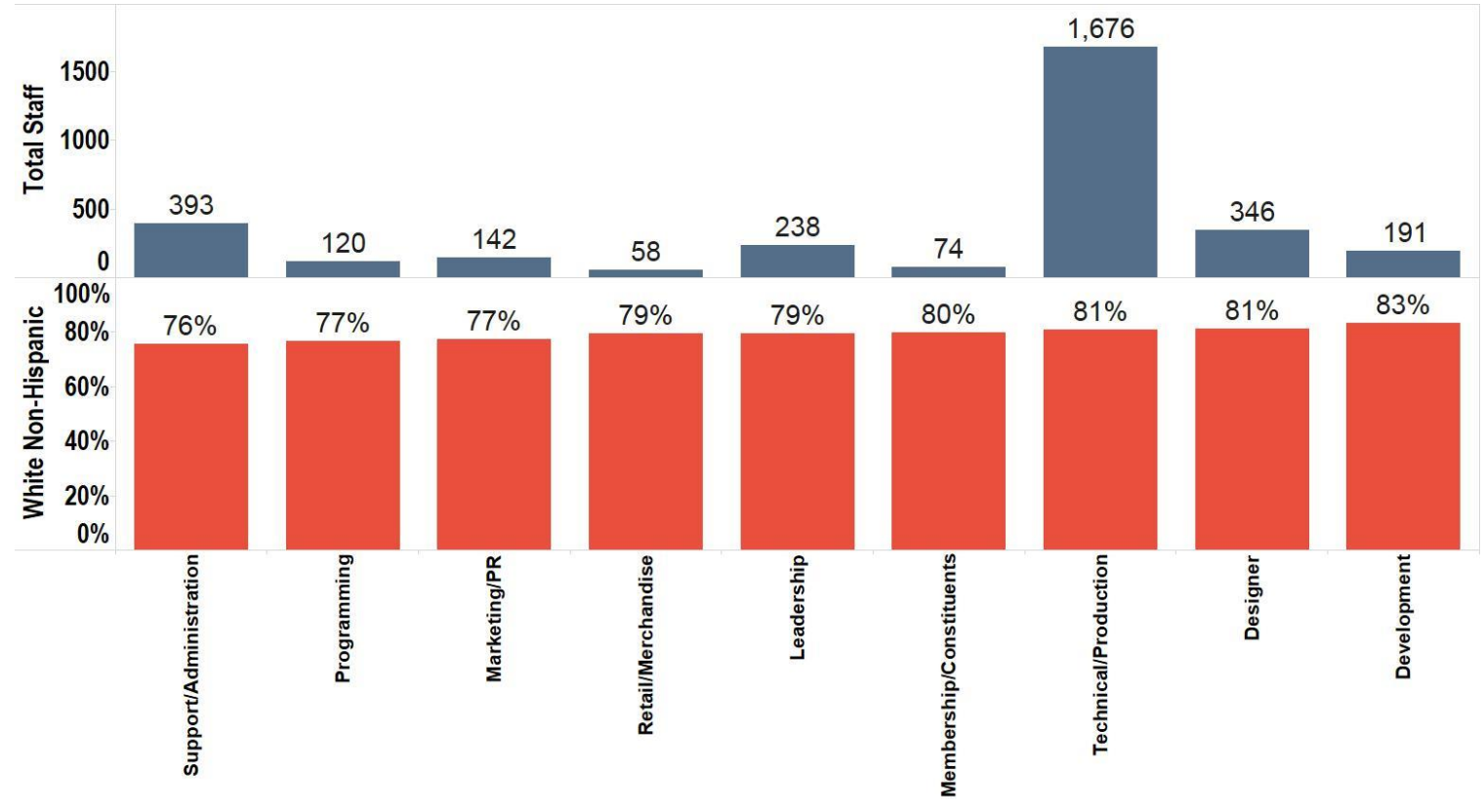


Figure 24 shows that museums in New York City map closely to the percentage of white non-Hispanic staff for North American museums in curatorial (84\%) and leadership (85\%) positions. Education is the largest job type for museums in New York, making up $14 \%$ of the work force. Educators are as diverse as the overall museum staff, about $60 \%$ white non-Hispanic. The second most common job type for museums is security, which is $40 \%$ white non-Hispanic, $34 \%$ black or African American.

Figure 24: Museum Job Categories over 75\% White Non-Hispanic

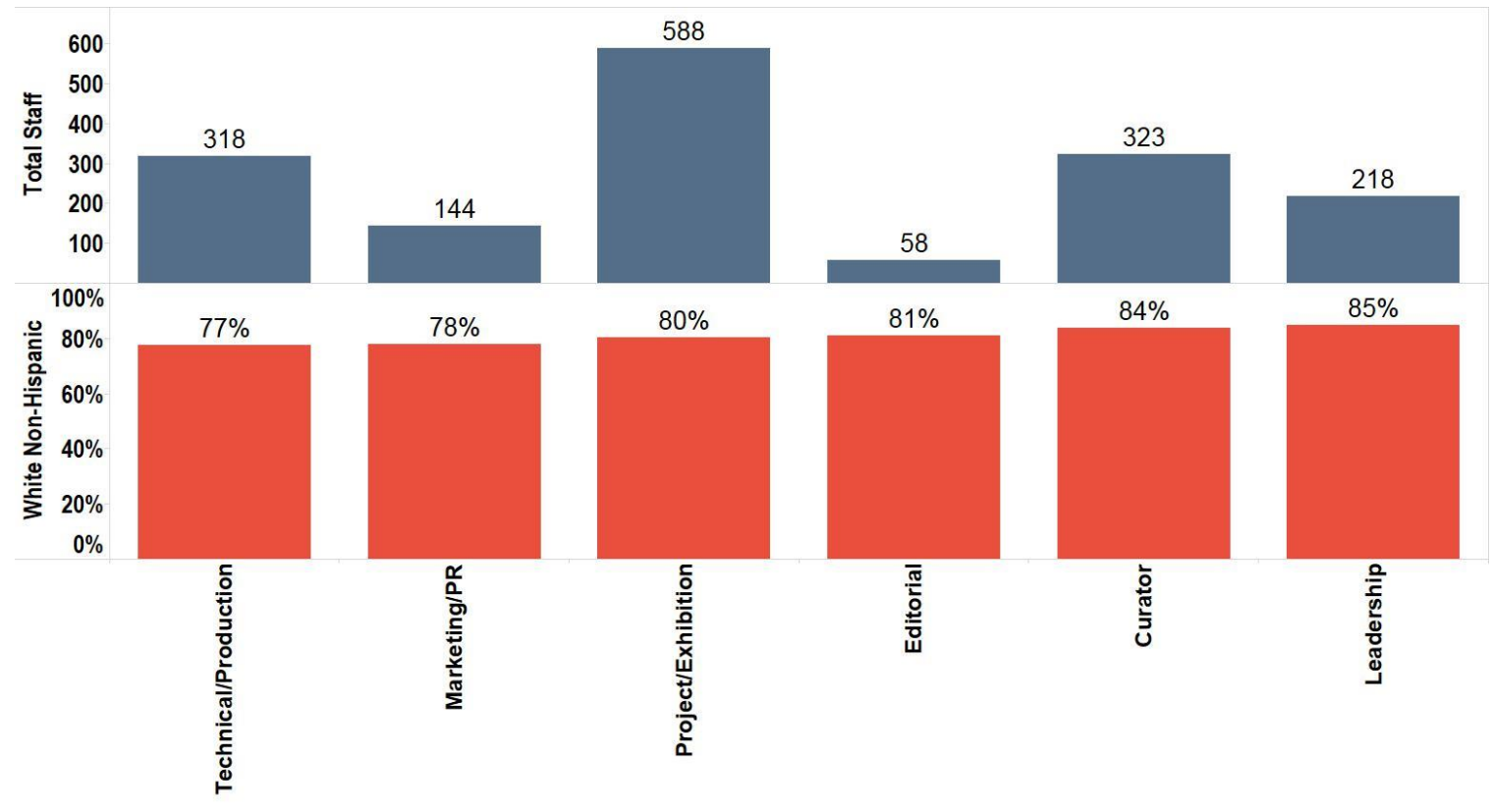




\section{Decade Born and Decade Hired}

Figure 25 shows that, by a relatively large margin, a plurality of employees of DCLA organizations were born in the 1980 s and hired in the last 5 years.

Figure 25: Decade Born Total and Percent White Non-Hispanic

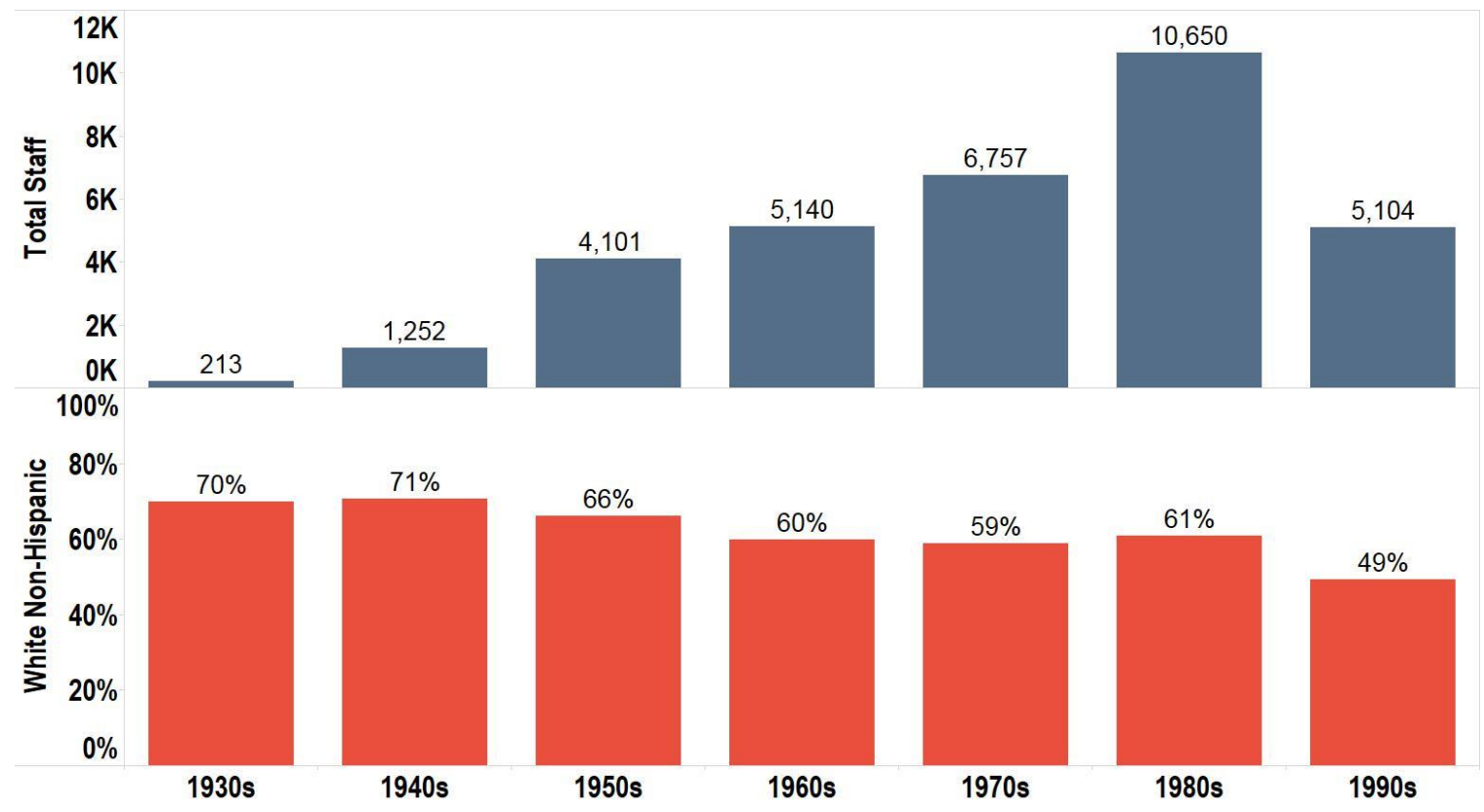


Figure 26 shows the total number of employees hired in a given decade, in relation to the percentage white non-Hispanic employees hired in that decade.

Figure 26: Decade Hired Total and Percent White Non-Hispanic

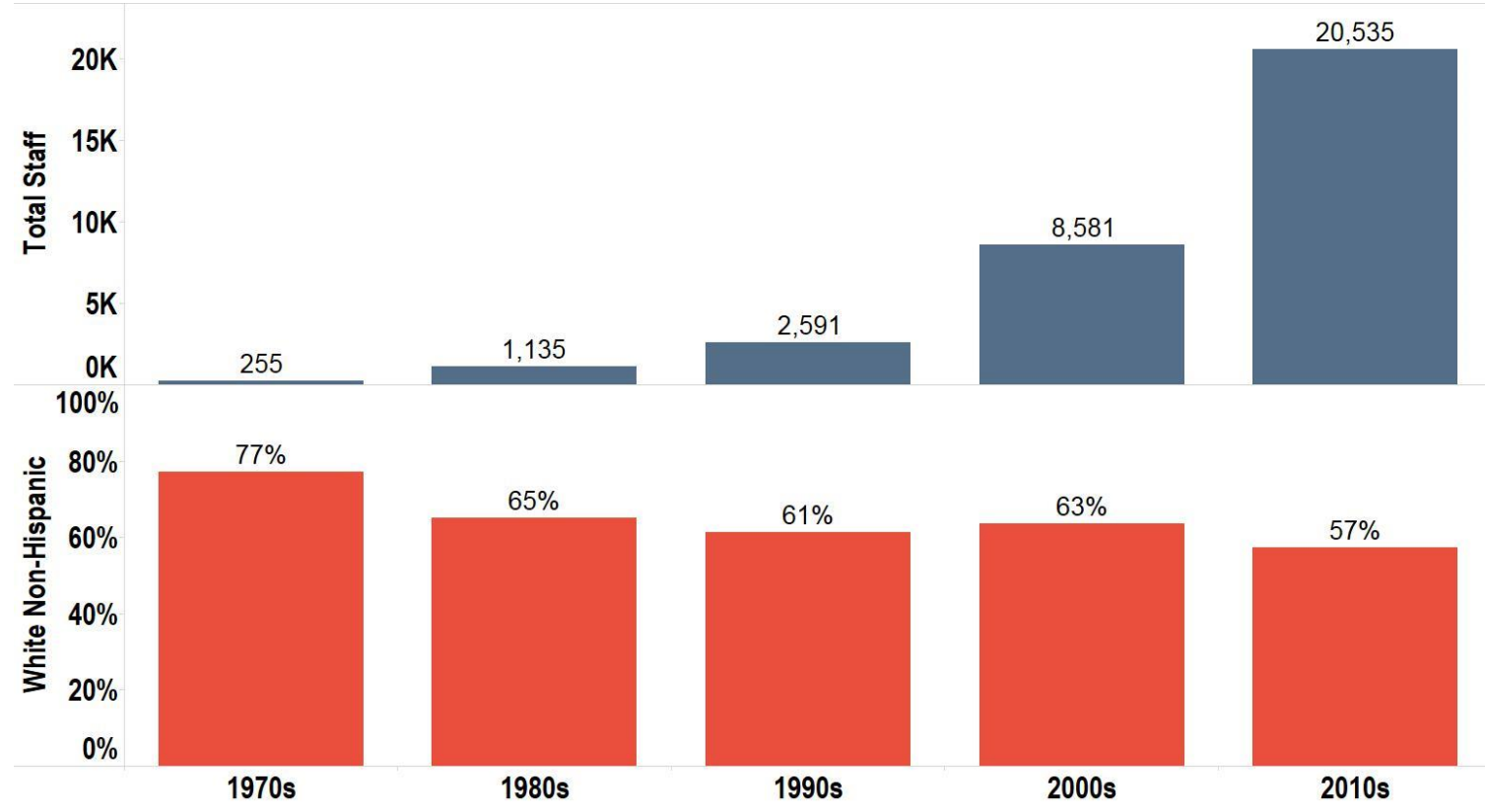

This tells us that the majority of employees working for DCLA are between 25 and 35, have been recently hired, and are the most racially diverse age group in DCLA. 
Figure 27 shows that from the 2000s to the 2010s there has been a spike in education positions in the community and also a significant increase in the number of minorities employed in that field. In the 2000 s education was $63 \%$ white non-Hispanic. In the 2010 it is $53 \%$. Education appears to be a growth area for racial and ethnic diversity in the DCLA community.

Figure 27: Education positions by Race/Ethnicity from 2000 s to $2010 \mathrm{~s}$

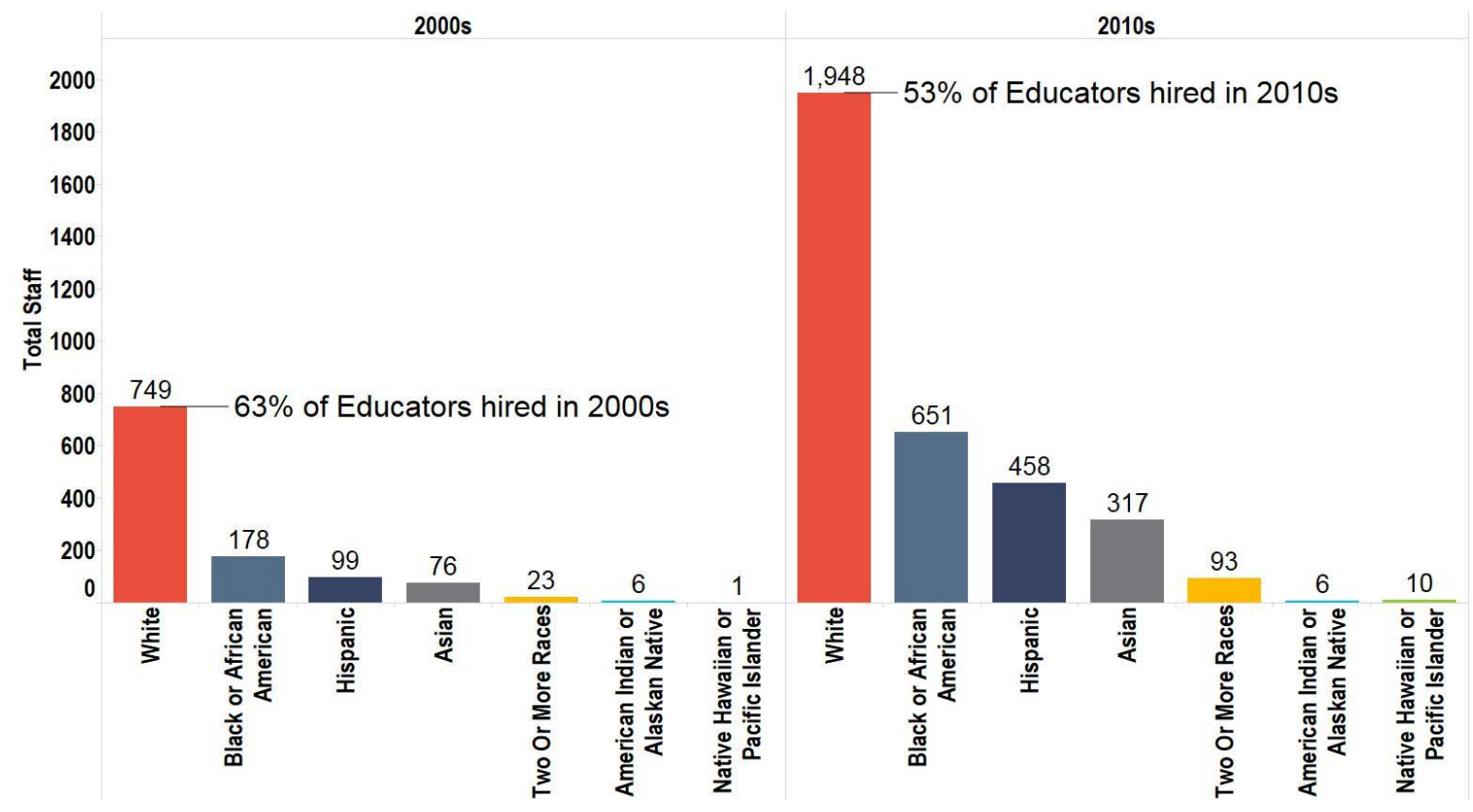


Figure 28 shows us that the majority of these positions across race and decade are parttime (though this is not true in the museum community, where education positions are closer to $50 \%$ part-time, $50 \%$ full-time). White non-Hispanic staff remain constant across decades, at around 25\% full-time. Minorities in aggregate are $18 \%$ full-time in the 2000 and $14 \%$ full-time in the 2010 .

Figure 28: Education positions, Full-Time (Blue) and Part-Time (Red) by Race/Ethnicity from 2000 to 2010 s

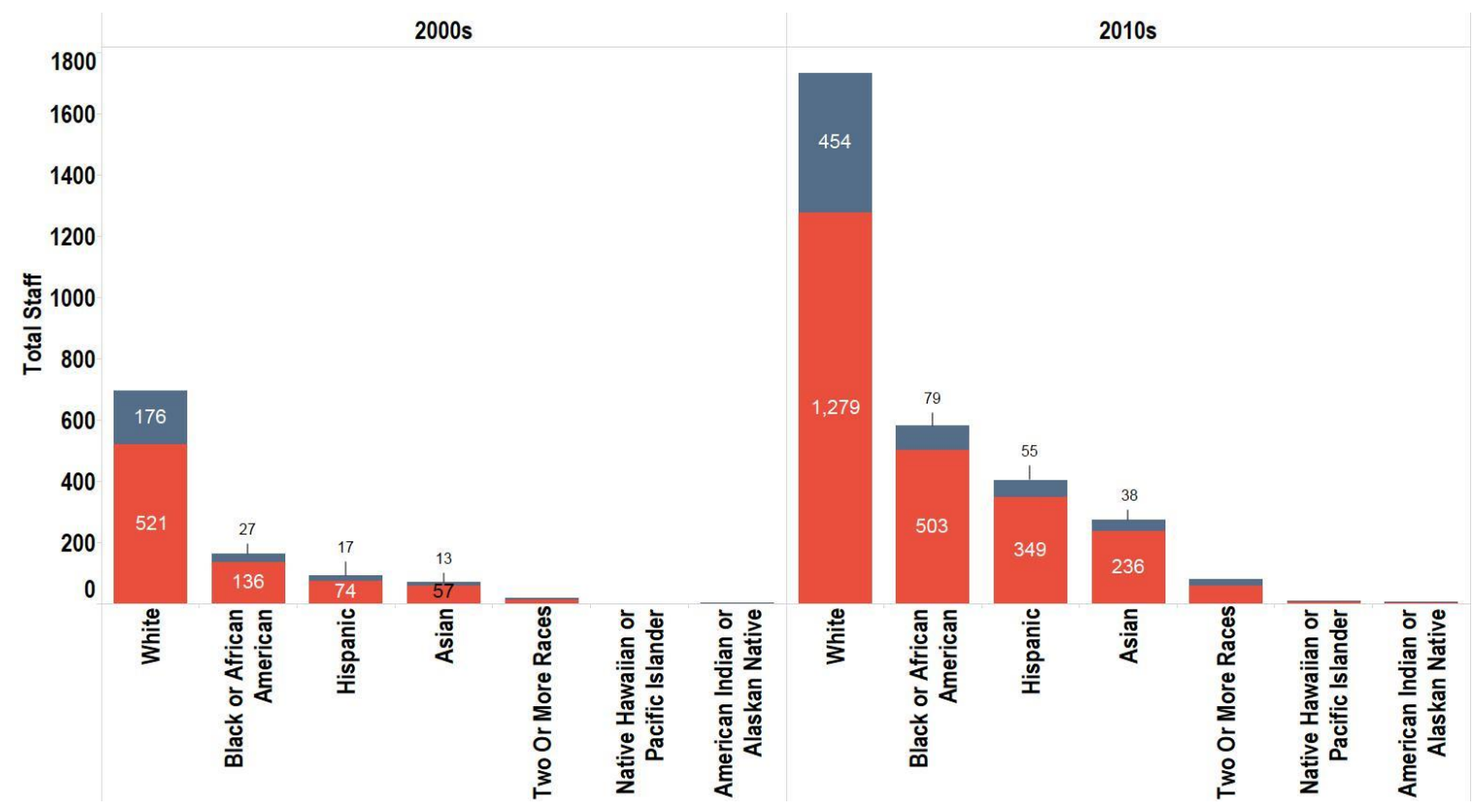




\section{Volunteer}

We also collected volunteer status. We heard from our advisory committee that for many DCLA funded organizations volunteers are critical to daily functions. Over 9,00o staff were reported as volunteers. Asians are $12 \%$ of the volunteer population, compared to 8\% of the total, as seen in Figure 29.

Figure 29: Volunteer Race/Ethnicity Percentage

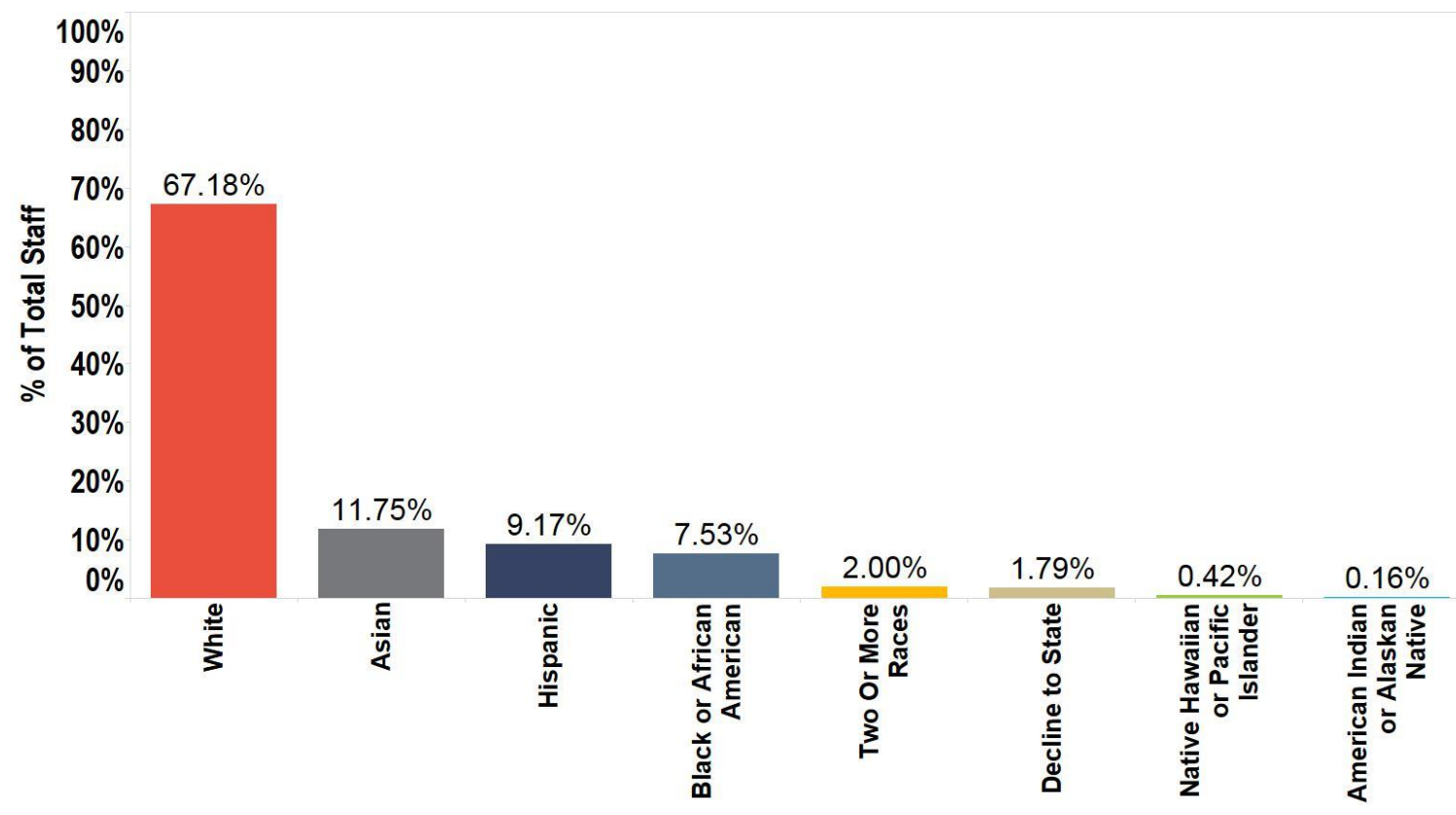


Figure 30 shows volunteers separated by the decade they were born. Red represents minorities and blue represents white non-Hispanic volunteers. Board members have been excluded. The graph shows us that volunteers in their 50s, 60s and 70s are between $70 \%$ and $90 \%$ white non-Hispanic, while younger volunteers in their 20 s and 30 are about half minority.

Figure 30: Volunteer Race/Ethnicity Percentage

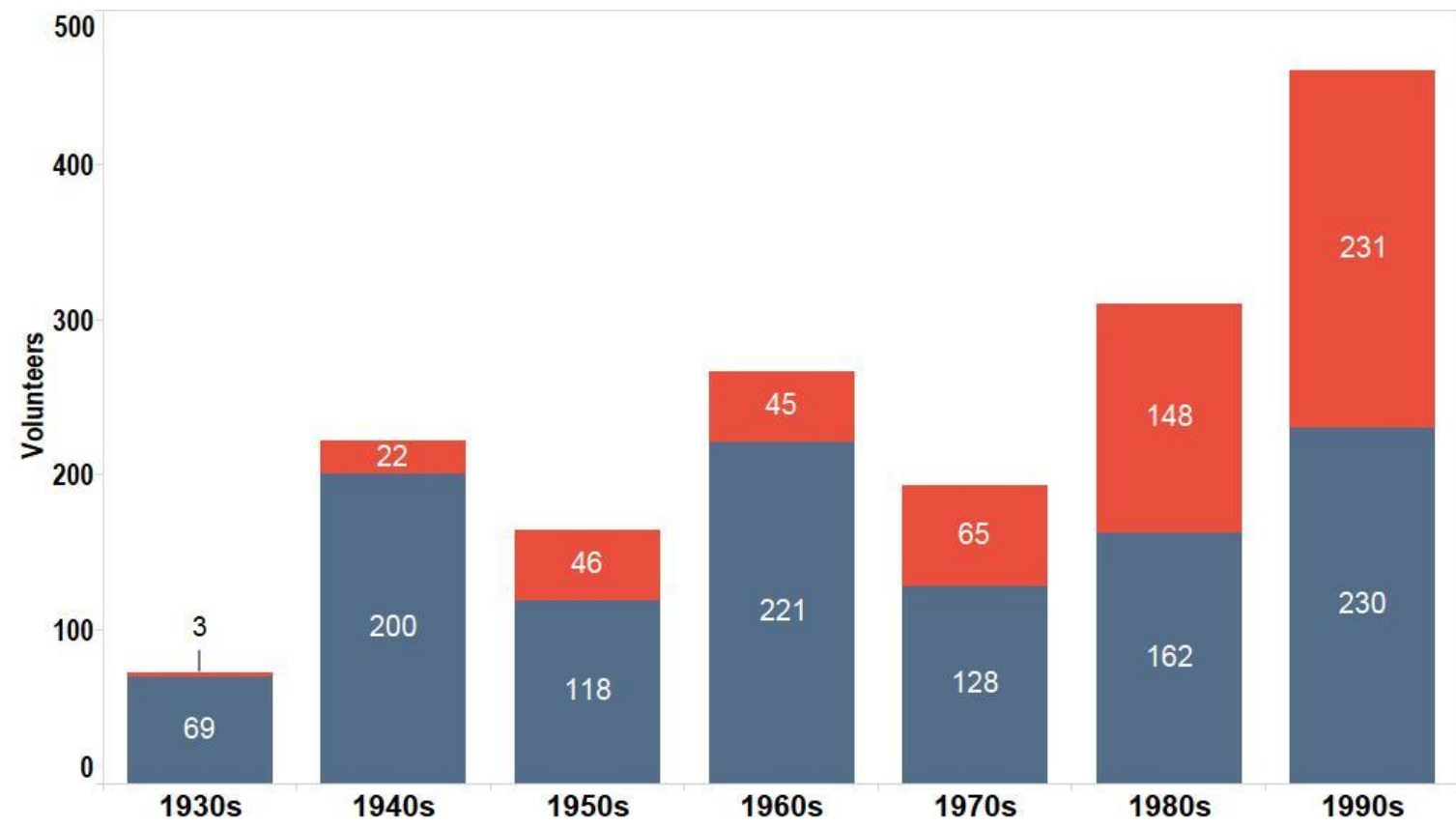




\section{Perceptions, Obstacles and Initiatives}

One benefit of the methodology mentioned above is that it provides an opportunity to compare self-perception within the community with the aggregated statistics reflecting the quantified racial/ethnic and gender characteristics of the group. In the questionnaire we asked organizations to choose whether they agreed or disagreed with the statement, "I feel my organization is diverse." As Table 4 shows, 69\% of organizations either agreed or strongly agreed with the statement. Only $8 \%$ disagreed or strongly disagreed.

Table 4: To what degree do you agree with the statement, "I feel my organization is diverse"?

\begin{tabular}{lll}
\hline Diverse & Total & Percent \\
\hline Strongly Agree & 269 & $27 \%$ \\
\hline Agree & 413 & $42 \%$ \\
\hline $\begin{array}{l}\text { Neither Agree nor } \\
\text { Disagree }\end{array}$ & 232 & $23 \%$ \\
\hline Disagree & 68 & $7 \%$ \\
\hline Strongly Disagree & 8 & $1 \%$ \\
\hline
\end{tabular}

\section{Barriers}

We asked organizations to weigh in on the barriers they face in increasing diversity in their organizations. Many mentioned socioeconomic issues. One respondent wrote that:

"We operate on a shoestring budget, and have trouble paying competitive salaries. As a result, job applicants are usually those who come from more privileged backgrounds and can afford to work for little money. This is our primary barrier to increasing staff diversity."

Socioeconomic status also registered high on a survey question about types of diversity that are important to the DCLA community, as seen in Figure Table 5 (page 42).

There was also a group of respondents who disagreed with the characterization of diversity in this survey. For instance, one respondent wrote: "We do not believe the 
above categories determine the quality of a person's work, and they are therefore not important for strengthening the quality of the work of our organization."

Broadly speaking, the qualitative findings reflect the quantitative-some organizations are enthusiastic about diversity in their workplace, some are confronting challenges and working towards goals of inclusion and equity, and some are indifferent towards, or in disagreement with, the claim that these efforts have value.

In the questionnaire portion of the survey $77 \%$ stated there were no barriers to increasing diversity among their organization's overall employees, $74 \%$ said there were no barriers specifically for senior employees, and $68 \%$ said there were no barriers for board diversity. Of those who said there were barriers, the majority for all three categories felt there was a "pipeline" issue, meaning they feel that the pool of competitive candidates for openings in their organizations has not been diverse.

\section{Initiatives}

We also asked whether the respondents had implemented successful initiatives meant to increase diversity. Sixty-eight percent said they had seen success with diversity initiatives. Of that group, most organizations reported that these were cultural programming initiatives (86\%) and community partnerships (78\%). Some had responses to the set of questions on diversity initiatives, which may be instructive for others in the community. Two organizations offered best practices for how they recruit diverse employees:

"We post openings on websites such as Diversity Jobs' to increase diverse submissions. About 1 in 3 hires are former interns. To diversify intern pools we work with and visit CUNY and HBCUs, speaking to students about the internship program and foster relationships with professors and departments.”

"We recruit diverse employees through partnerships with colleges serving diverse student populations; recruiting through websites and career fairs focused on serving diverse job seekers such as Latino Public Radio Consortium, National Association of Black Journalists, and OUT jobs.”

Since many organizations in the "barriers" portion of the survey expressed difficulty circumventing pipeline issues, it was encouraging to see that some respondents had resources they turned to toward that end.

${ }^{9}$ Our Company, accessed January 14, 2016, http://diversityjobs.com/about/our-company. 
Many organizations also reported in the free text portion of the survey that they have begun to focus on diversity in a more systematic way. For instance, one organization stated that,

"This summer [we] launched [our] first ever structured learning and development program for all employees. The workshop that was selected to launch this high profile initiative was Managing Diversity. A staff run Equity and Inclusion Task Force was recently formed. It will assist senior employees in implementing HR policies which guarantee transparency, fairness and improved morale."

Others have focused on hiring full-time staff positions to engage with these issues. Another organization reports:

"[This summer we] hired a full-time Equity and Inclusion Coordinator who works across research, convening, and technology program areas, and is currently focused on activities to increase racial equity and expand access and inclusion for disabled New Yorkers in the field."

There are certainly leaders in this community who are engaging with issues of diversity in an open way, and it will be interesting to see the results of their work on this issue.

\section{Disability}

The excel spreadsheet portion of the survey included a field for disability status. We knew this could pose difficulties-many organizations do not keep these records on file, and participants were asked not to try to guess on any part of the excel spreadsheet, but rather use existing personnel files. We were nonetheless surprised to receive nearly no records of anyone with a disability out of the 48,280 employees, volunteers and board members who were recorded. This confirms what was recently reported in "Discovering Disability: Data \& NYC Dance.”10 One key finding of their extensive study of disability issues was that there is very little useful data on the subject. As they say, "The data sources used, individually and collectively, proved insufficient to meaningfully address the scope of inquiry and assess the state of disability and dance. Better and more uniform data on programs, education and facilities, and, critically, demographic data to illuminate the role of disabled people in the workforce and in the audience, are requisite to advancing an inclusion and equity agenda."

10 Elissa Hecker and Lane Harwell, "Discovering Disability: Data \& NYC Dance," www.dance.nyc, May 28, 2015. accessed January 14, 2016, http://www.dance.nyc/uploads/DanceNYC-ReportDisability-Final(Linco).pdf. 
One of the questions on the survey asked respondents what kinds of diversity were important for their organization's work. The question was multiple select, meaning that organizations could choose all of the options if they wanted to. Disability registered 2227 percentage points below the other variables we collected in the spreadsheet portion of the survey as seen in Table 5 (page 42).

But many organizations reported that they are aware and striving towards inclusion and equity for the disabled community. Here is one response representative of many organizations who chose to describe their best practices concerning disability:

"[Our] website uses a responsive template design optimized for multiple screen sizes and screen readers to ensure accessibility by people with visual impairments. We also provide transcripts of all broadcast content to ensure accessibility by people with hearing impairments."

Analyzing disability in a quantitative way is undoubtedly a challenge. But addressing disability issues on an organizational level remains important, and many in the DCLA community are deeply engaged in this process.

\section{Conclusion}

We asked respondents what types of diversity are important to improving the quality of work at their organizations. This was a multiple select question, meaning respondents could select as many options as they liked. Types of diversity appear to have separated into two distinct categories. Around 80\%-90\% of respondents selected race, ethnicity, gender, age, and socioeconomic status. Socioeconomic status was the only category in that range $80 \%$ that wasn't a part of our data collection instrument.

LGBTQ, Disability, Language, Immigrant/Refugee and Religious diversity were selected less frequently, at $71 \%, 63 \%, 60 \%, 53 \%$ and $44 \%$. 
Table 5: "What types of diversity are important to improving the quality of work at your organization?”

\begin{tabular}{lll}
\hline Type of Diversity & Total & Percent \\
\hline Ethnicity & 886 & $90 \%$ \\
\hline Race & 869 & $88 \%$ \\
\hline Age & 852 & $86 \%$ \\
\hline Gender & 841 & $85 \%$ \\
\hline Socioeconomic & 790 & $80 \%$ \\
\hline LGBTQ & 702 & $71 \%$ \\
\hline Disability & 626 & $63 \%$ \\
\hline Language & 591 & $60 \%$ \\
\hline Immigrant/Refugee & 522 & $53 \%$ \\
\hline Religious & 432 & $64 \%$ \\
\hline Other & 60 & $6 \%$ \\
\hline
\end{tabular}

While this table shows some stratification in types of diversity organizations find important, it also emphasized that most organizations value many types of diversity. This level of interest shows that many cultural organizations in New York agree that issues of equity and inclusion are relevant to their work.

Overall, the strong participation of the DCLA grantee community in this project is a testament both to the Department's prioritization of diversity and the community's strong interest and engagement. The findings represent a snapshot of the DCLA grantee community in the summer of 2015, against which the New York City cultural community and its policy makers can gauge the current position. As time progresses, and to the extent that interventions are put into place, these findings also provide a strong baseline to measure change over time. 